\title{
Connecting smoke plumes to sources using Hazard Mapping System (HMS) smoke and fire location data over North America
}

Steven J. Brey et al.

Correspondence to: Steven J. Brey (sjbrey@ rams.colostate.edu)

The copyright of individual parts of the supplement might differ from the CC BY 3.0 License. 


\section{S1 HYSPLIT Trajectories detailed description}

The HYSPLIT (Hybrid Single Particle Lagrangian Integrated Trajectory) trajectory model simulates air parcel movement by wind advection using spatially and temporally gridded meteorology data, and it is used to establish source-receptor relationships [Draxler and Hess, 1998; Stein et al., 2015]. The model computational method is a hybrid between Lagrangian and Eulerian reference frames [Stein et al., 2015]. HYSPLIT has been used extensively to model the transport of smoke (e.g., [Stein et al., 2015]). The model executable is available for download on the NOAA Air Resources Laboratory (ARL) webpage http: //ready.arl.noaa.gov/hyreg/HYSPLIT_pchysplit.php.

Based on numerical and physical limitations of the model, the error in the location of a trajectory is approximately $15-30 \%$ of the distance traveled by the air parcel [Draxler, 2008]. The physical error is related to how well the numerical values (e.g. $\mathrm{u}$ and $\mathrm{v}$ winds) represent the true state of the atmosphere. The numerical error arises from integration error, truncation, and the fact that calculations of continuous variables are being done on a discrete grid [Draxler, 2008]. We present results generated using the 32 bit Windows PC executable version of the trajectory model (hyts_std.exe) on a Debian Unix cluster at Colorado State University using the WINE (Wine Is Not an Emulator; https://www.winehq.org) compatibility layer. A Python based HYSPLIT manager system allows each available core to independently call the HYSPLIT trajectory executable. Six-day (144-hr) forward trajectories are calculated for each HMS HYSPLIT point using meteorological data from the GDAS (Global Data Assimilation System) archive, which has a time step of 3-hours, horizontal grid spacing of $1^{\circ}$ latitude by $1^{\circ}$ longitude $(120 \mathrm{~km})$, and a vertical grid spacing of 23 pressure surfaces between 1000 and $20 \mathrm{hPa}$. Vertical layers 1-5 are separated by $25 \mathrm{hPa}$. All higher layers (with the exception of the top layer) are separated by $50 \mathrm{hPa}$ [Kanamitsu, 1989]. The GDAS 1-degree archived data is available for download at: ftp://arlftp.arlhq.noaa.gov/pub/archives/gdas1. Six-day trajectories are also calculated for each HYSPLIT point in the data domain (excludes Alaska, parts of Canada and Mexico) using meteorological data from the EDAS (Eta Data Assimilation System) archive. This data has a 3-hour time step, horizontal grid spacing of $40 \mathrm{~km} \mathrm{x} 40 \mathrm{~km}$, and 26 pressure surfaces between 1000 and $50 \mathrm{hPa}$. EDAS40 archived data is available for download at: ftp://arlftp.arlhq.noaa.gov/pub/archives/edas40.

In this work, forward HYSPLIT trajectories are initialized from each of the HYSPLIT points over the duration of the fires to represent likely smoke transport. Practically, this means that for HYSPLIT points assigned durations of 0 - 6 hours, one trajectory is initialized at the middle hour between the first and last hour. For HYSPLIT points with durations of 7 - 12 hours, two trajectories are initialized at the 25th and 75th percentile of the span of hours over the duration of the fire. For durations of 13 - 18 hours, three trajectories are initialized at the 20th, 50th, and 80th percentile of the span of hours between start time and end time. For durations of 19 - 24 hours, four trajectories are initialized at the 20th, 40th, 60th, and 80th percentile of the span of hours. Trajectories are not initialized at the start or finish hours because many of the HYSPLIT points have durations of 24 hours, last multiple days, and are re-detected daily, so initializing trajectories at the time fires are detected would overweight early morning hours when HYSPLIT points are first detected with visible satellite imagery. This is a concern because the most common duration for the HYSPLIT points is 24 hours (manuscript Fig. $2 \& 9$ ). 
Table S1: Trajectories initialized for GDAS1 HYSPLIT runs following the strategy outlined in Sect S1. The third column is the percent of initiated trajectories that reach $0 \mathrm{~m}$ within the 6 day calculation. These trajectories are subset and only considered for the hours before they reach $0 \mathrm{~m}$. The minimum number of trajectories that can be run for a HYSPLIT point is 3 (heights); the maximum is 12 (4 start times for a 24-hour duration at 3 initialization heights). The number of trajectories for each year includes all months.

\begin{tabular}{c|c|c} 
Year & Unique trajectories (total with duplicates) & \% reaching 0 m \\
\hline 2007 & $460209(546377)$ & 4.2 \\
2008 & $433671(482816)$ & 4.9 \\
2009 & $210089(226872)$ & 5.9 \\
2010 & $379568(417395)$ & 8.2 \\
2011 & $494375(563040)$ & 8.3 \\
2012 & $481438(563915)$ & 9.7 \\
2013 & $544463(598368)$ & 8.5 \\
2014 & $494320(527149)$ & 8.0
\end{tabular}

Table S2: Same as Table S1 but for EDAS $40 \mathrm{~km}$ meteorology data. Fewer trajectories were run due to the limited domain of EDAS $40 \mathrm{~km}$. Parts of Alaska, Northern Canada, and Southern Mexico are not included in this reanalysis dataset. The number of trajectories for each year includes all months.

\begin{tabular}{c|c|c} 
Year & Unique trajectories (total with duplicates) & \% reaching $0 \mathrm{~m}$ \\
\hline 2007 & $412930(496592)$ & 3.4 \\
2008 & $356785(397645)$ & 3.1 \\
2009 & $156219(169415)$ & 4.3 \\
2010 & $255939(287771)$ & 7.6 \\
2011 & $451102(525644)$ & 9.3 \\
2012 & $427541(506334)$ & 19.7 \\
2013 & $375993(423159)$ & 17.3 \\
2014 & $215841(231218)$ & 15.6
\end{tabular}

\section{S2 HYSPLIT point seasonality and location figures for non-CONUS regions:}

Manuscript Fig. 9 shows only U.S. regions. Here we provide versions of these figures for all regions shown in Fig. 6. All figures were generated using the same methodology described in Sect 4 of the manuscript. 

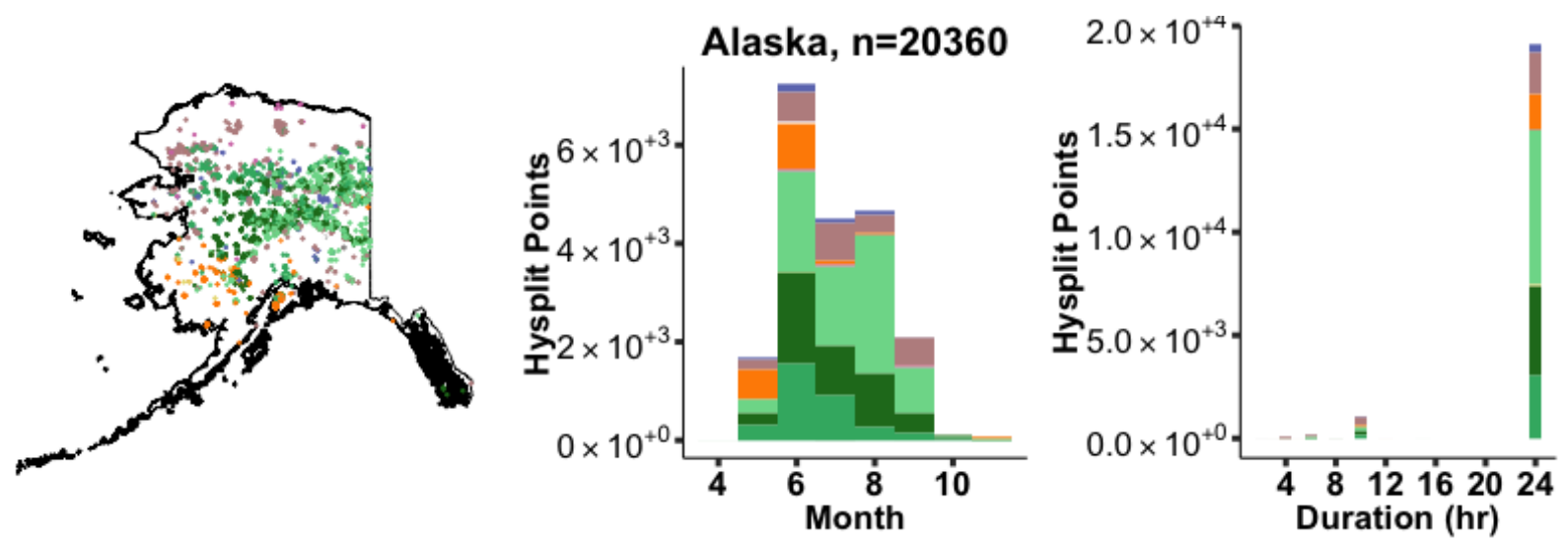

(a)
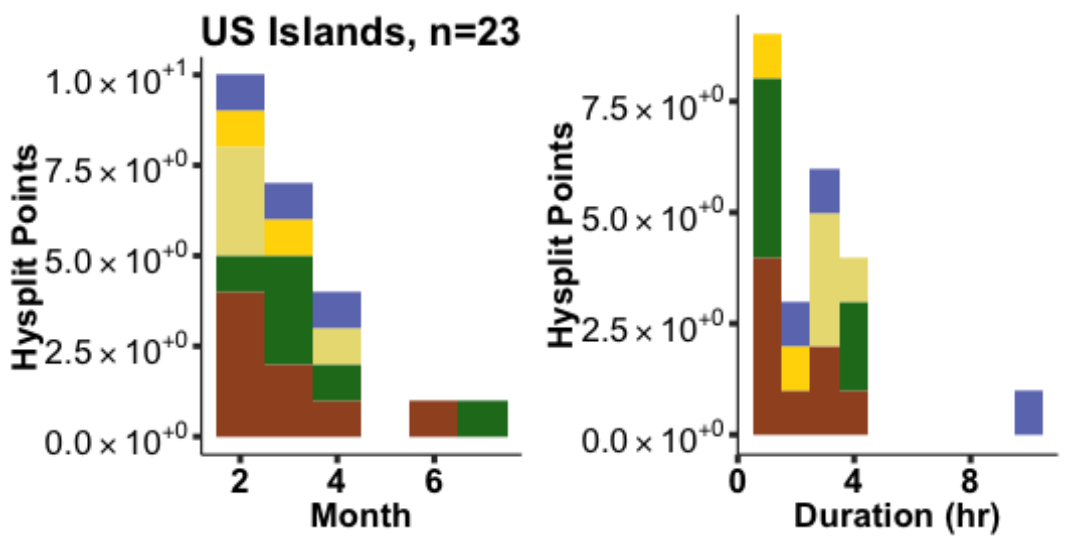

(b)
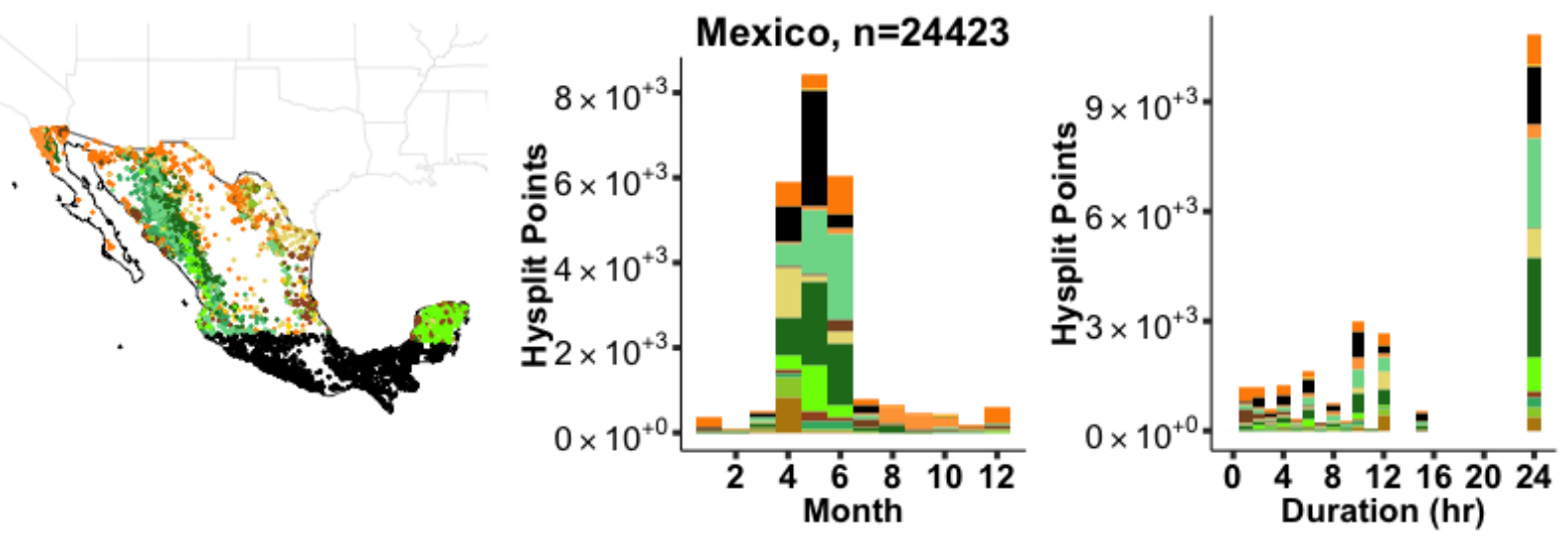

(c)

\begin{tabular}{|c|c|c|}
\hline $\begin{array}{l}\text { Land Cover } \\
\text { Barren or Sparsely Vegetated } \\
\text { Cropland/Grassland Mosaic }\end{array}$ & $\begin{array}{l}\text { Evergreen Needleleaf Forest } \\
\text { Grassland } \\
\text { Irrigated Cropland and Pasture }\end{array}$ & $\begin{array}{l}\text { Savanna } \\
\text { Shrubland } \\
\text { Snow or Ice }\end{array}$ \\
\hline Cropland/Woodland Mosaic & Mixed Forest & Unlabelled land area \\
\hline Deciduous Broadleaf Forest & Mixed Shrubland/Grassland & Wooded Tundra \\
\hline $\begin{array}{l}\text { Dryland Cropland and Pasture } \\
\text { Evergreen Broadleaf Forest }\end{array}$ & $\begin{array}{l}\text { Mixed Tundra } \\
\text { InoAssignment }\end{array}$ & Wooded Wetland \\
\hline
\end{tabular}



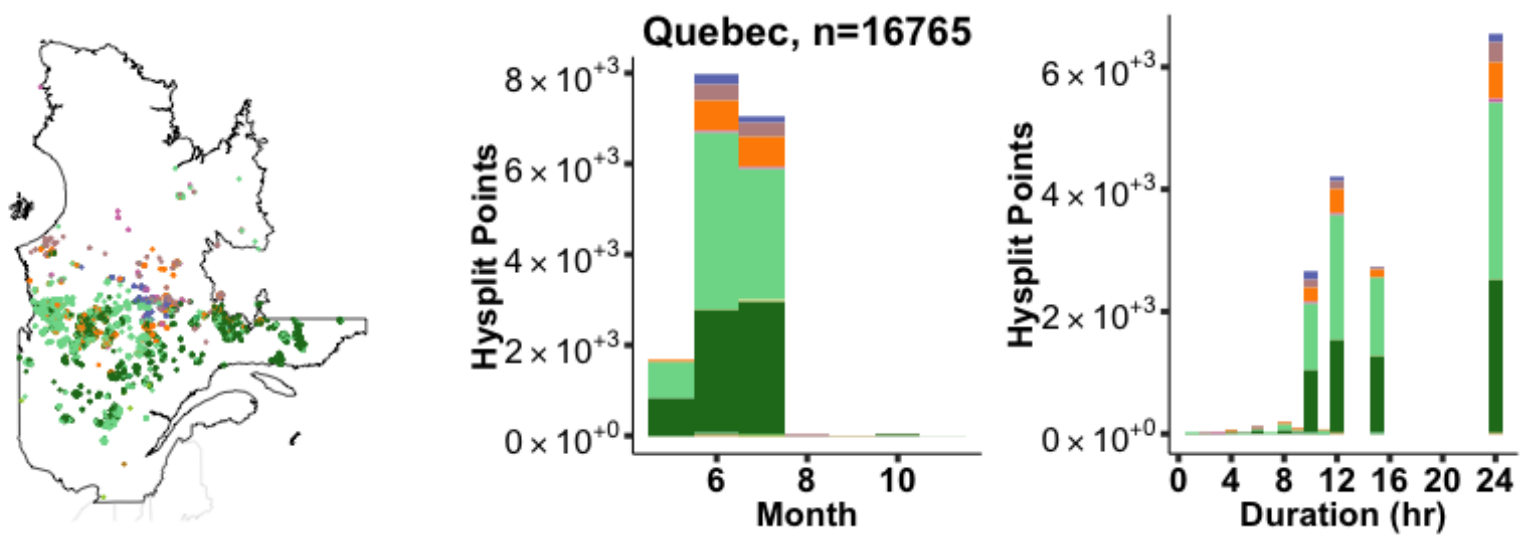

(d)
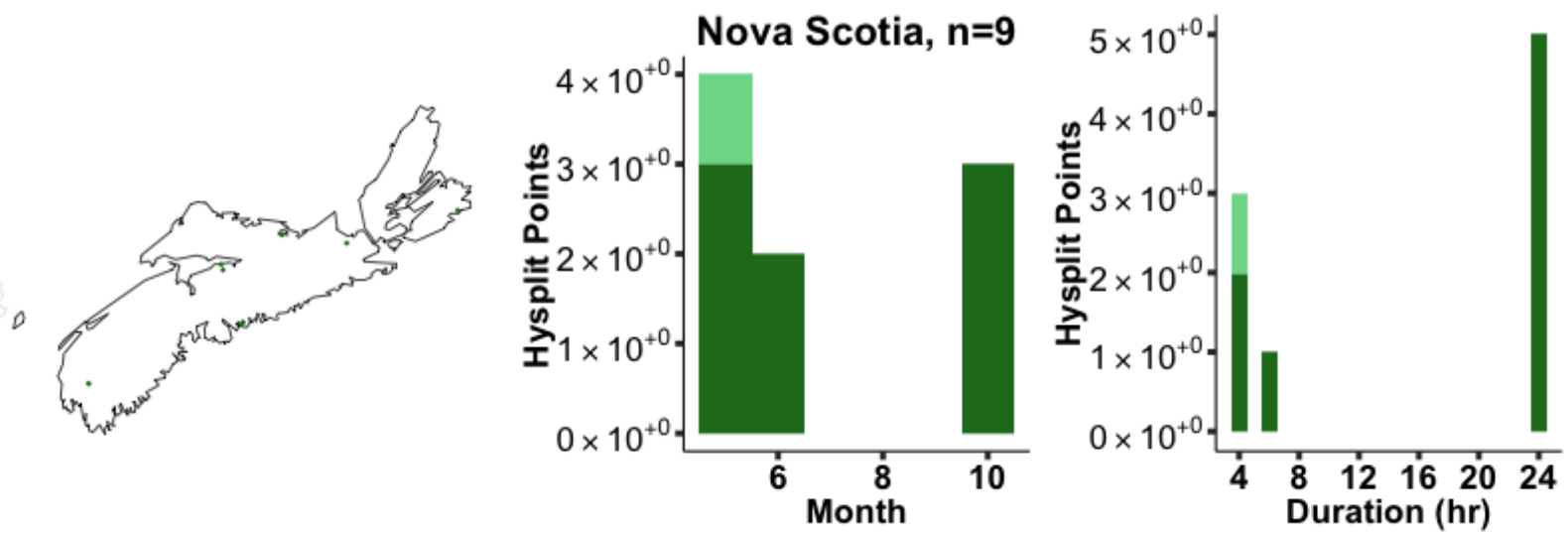

(e)
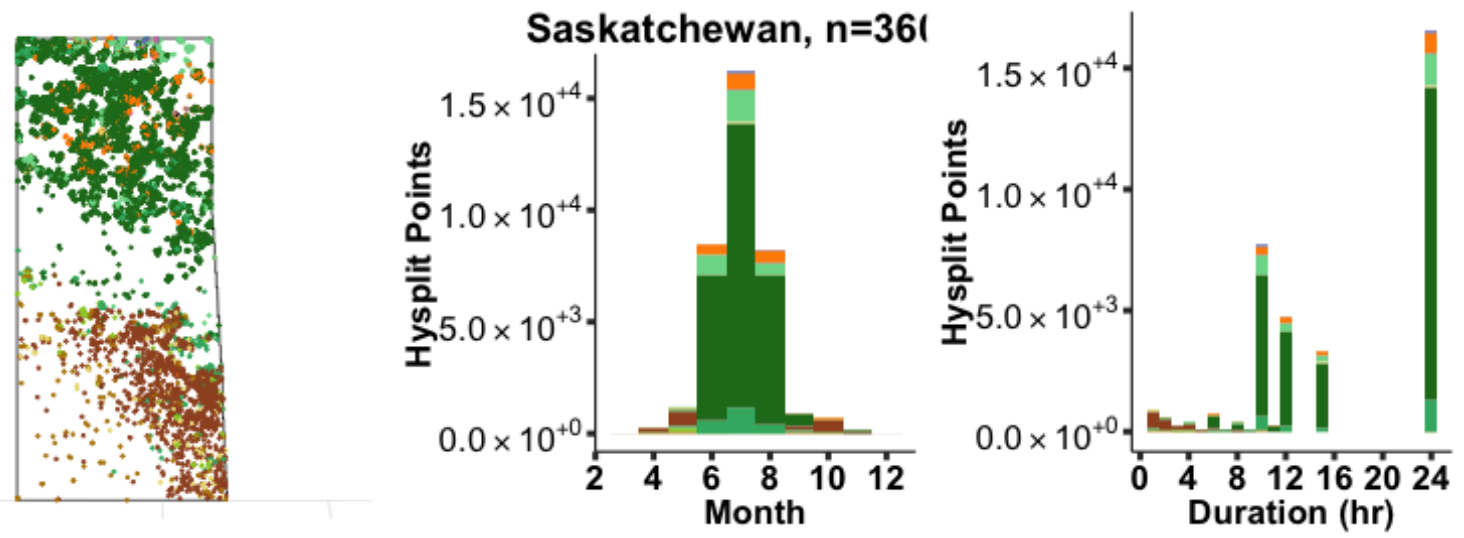

(f)

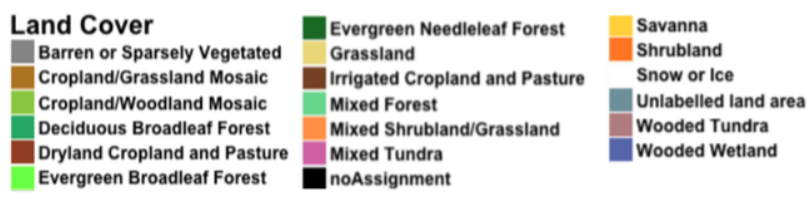



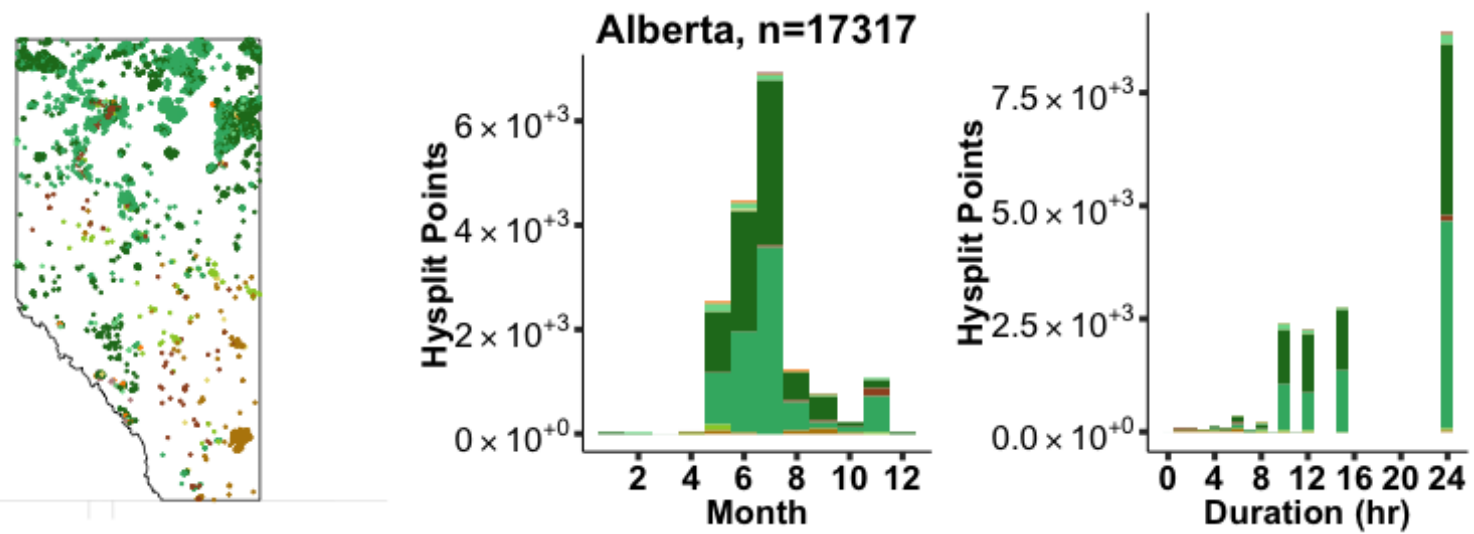

(g)

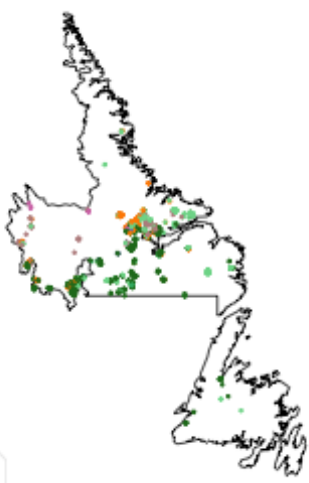

Newfoundland, $n=23$
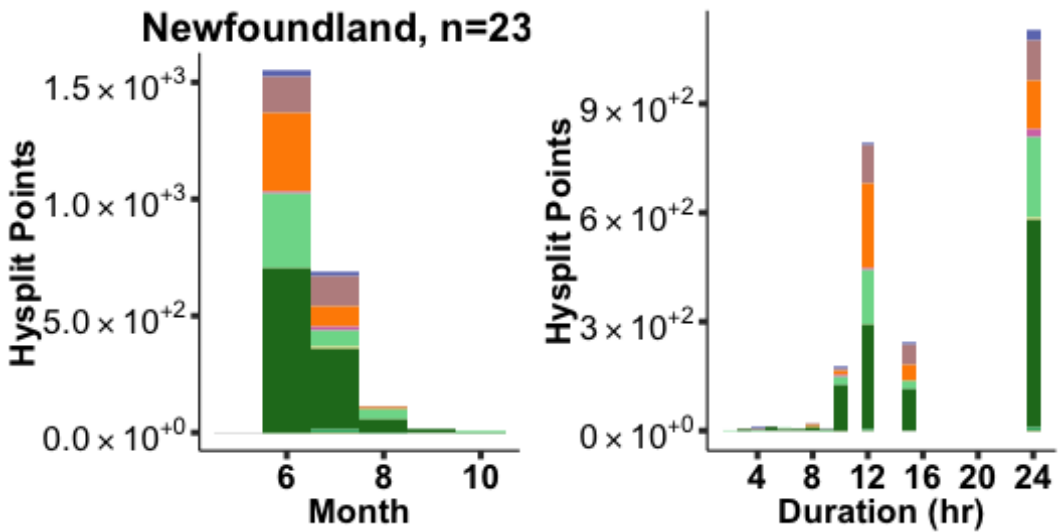

(h)
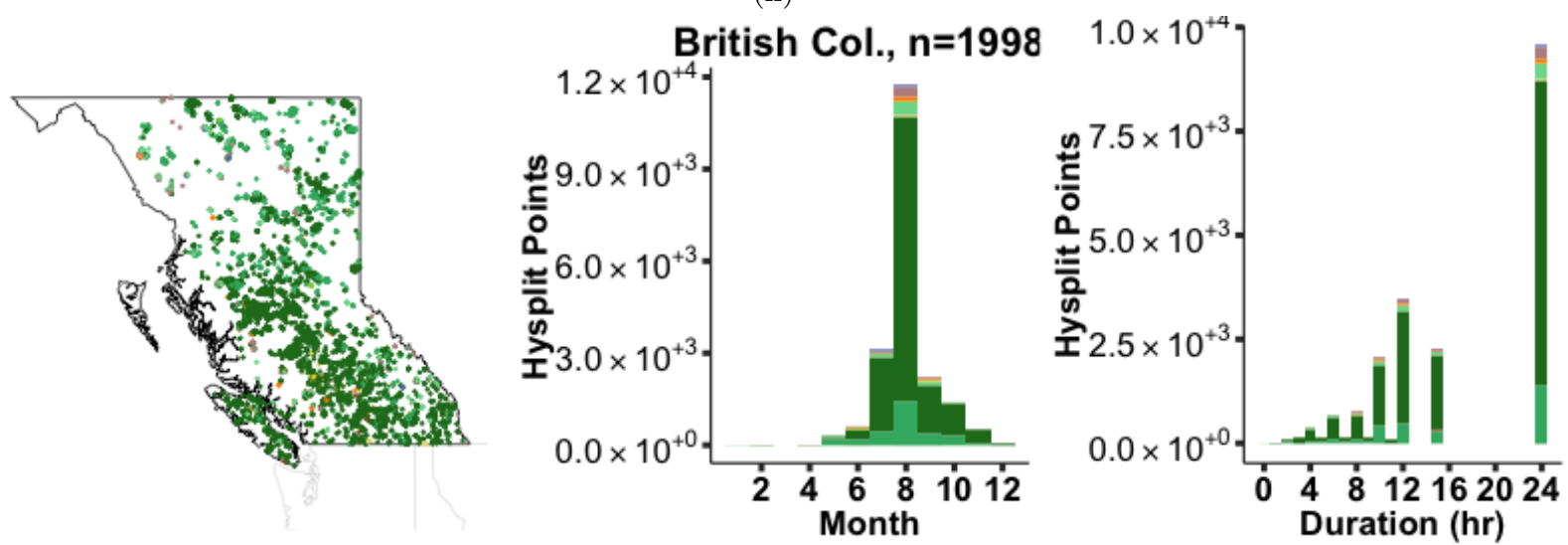

(i)

\begin{tabular}{|c|c|c|}
\hline $\begin{array}{l}\text { Land Cover } \\
\text { Barren or Sparsely Vegetated } \\
\text { Cropland/Grassland Mosaic }\end{array}$ & $\begin{array}{l}\text { Evergreen Needleleaf Forest } \\
\text { Grassland } \\
\text { Irrigated Cropland and Pasture }\end{array}$ & $\begin{array}{l}\text { Savanna } \\
\text { Shrubland } \\
\text { Snow or Ice }\end{array}$ \\
\hline Cropland/Woodland Mosaic & Mixed Forest & Unlabelled land area \\
\hline Deciduous Broadleaf Forest & Mixed Shrubland/Grassland & Wooded Tundra \\
\hline $\begin{array}{l}\text { Dryland Cropland and Pasture } \\
\text { Evergreen Broadleaf Forest }\end{array}$ & $\begin{array}{l}\text { Mixed Tundra } \\
\text { noAssignment }\end{array}$ & Wooded Wetland \\
\hline
\end{tabular}



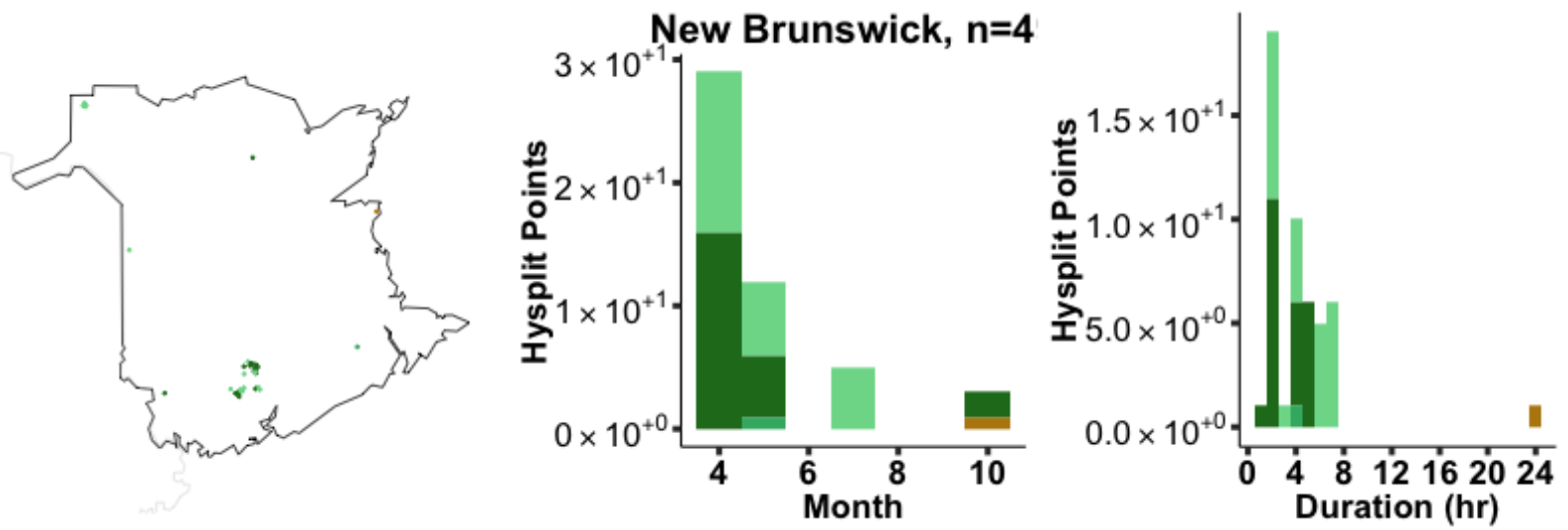

(j)

Prince Edward Island, $\mathrm{n}=0$
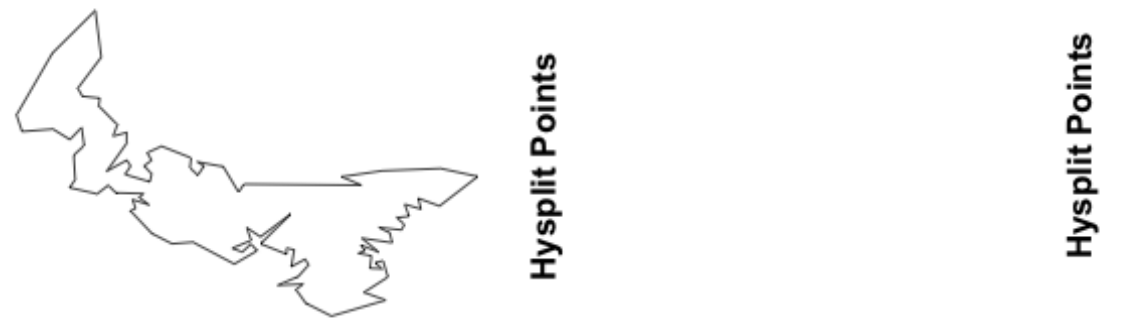

Month

(k)

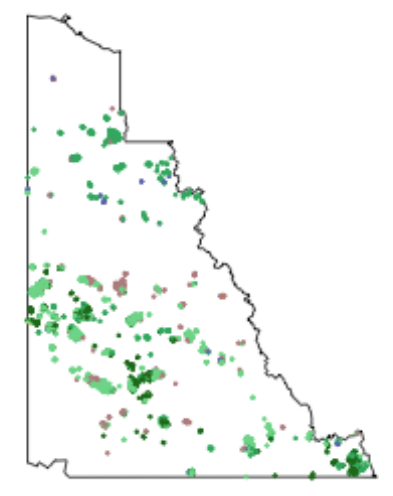

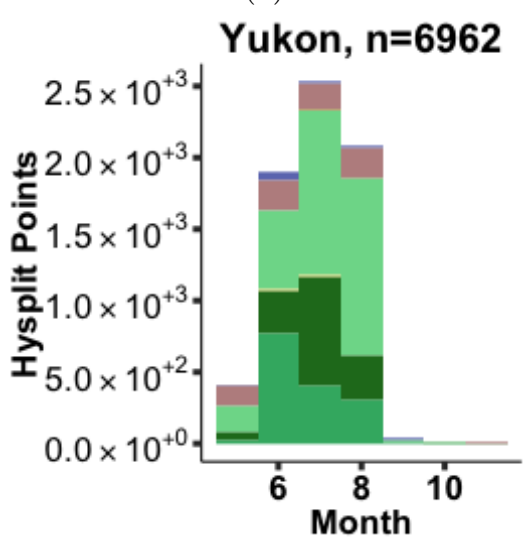

(1)

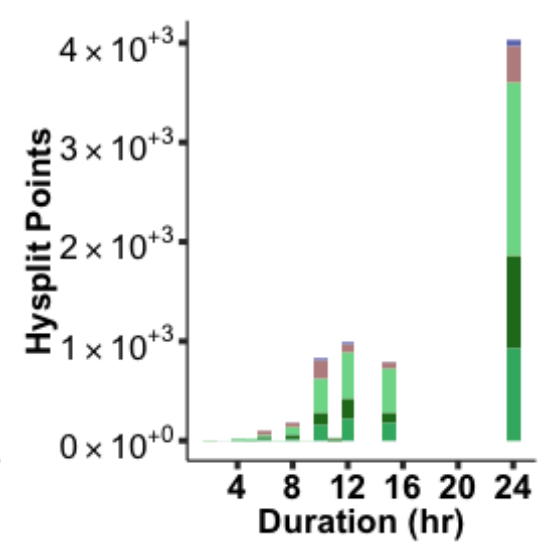

Duration (hr)

\begin{tabular}{|c|c|c|}
\hline $\begin{array}{l}\text { Land Cover } \\
\text { Barren or Sparsely Vegetated } \\
\text { Cropland/Grassland Mosaic }\end{array}$ & $\begin{array}{l}\text { Evergreen Needleleaf Forest } \\
\text { Grassland } \\
\text { Irrigated Cropland and Pasture }\end{array}$ & $\begin{array}{l}\text { Savanna } \\
\text { Shrubland } \\
\text { Snow or Ice }\end{array}$ \\
\hline Cropland/Woodland Mosaic & Mixed Forest & Unlabelled land area \\
\hline $\begin{array}{l}\text { Deciduous Broadleaf Forest } \\
\text { Dryland Cropland and Pasture }\end{array}$ & $\begin{array}{l}\text { Mixed Shrubland/Grassland } \\
\text { Mixed Tundra }\end{array}$ & $\begin{array}{l}\text { Wooded Tundra } \\
\text { Wooded Wetland }\end{array}$ \\
\hline Evergreen Broadleaf Forest & noAssignment & \\
\hline
\end{tabular}



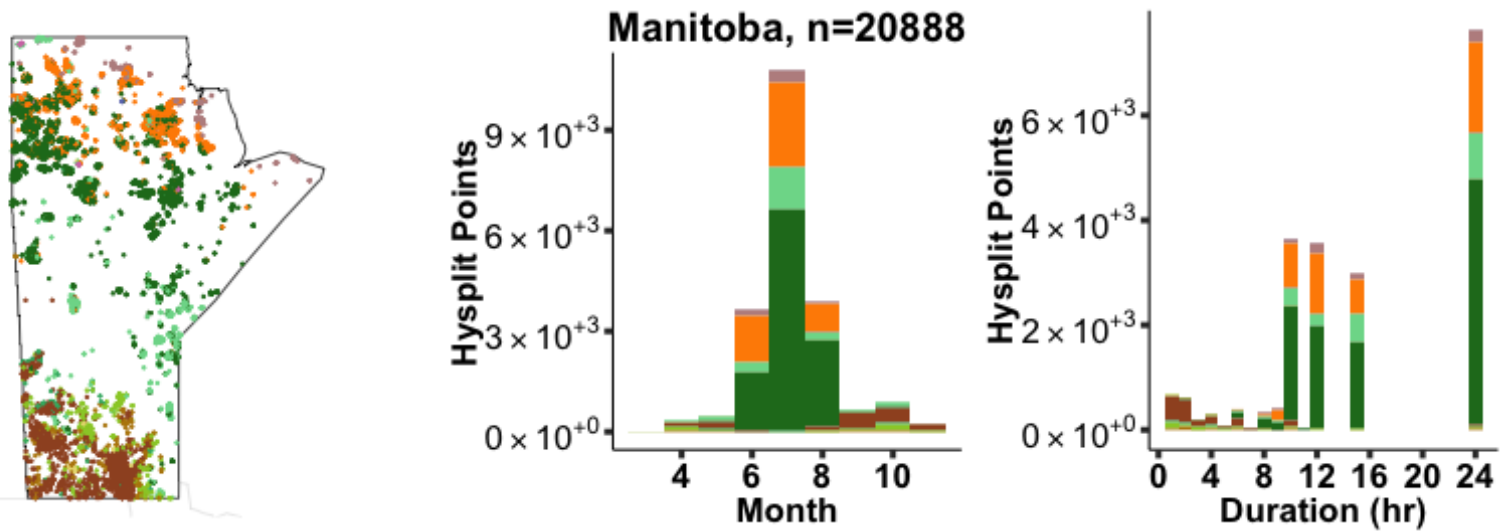

(m)
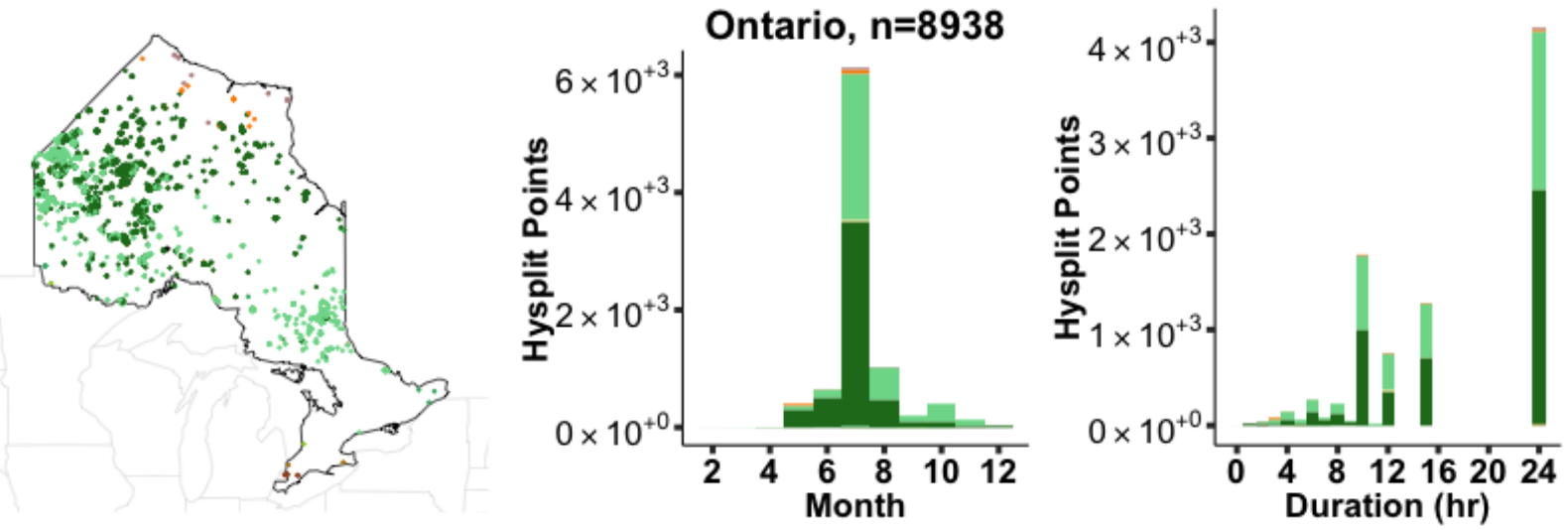

(n)
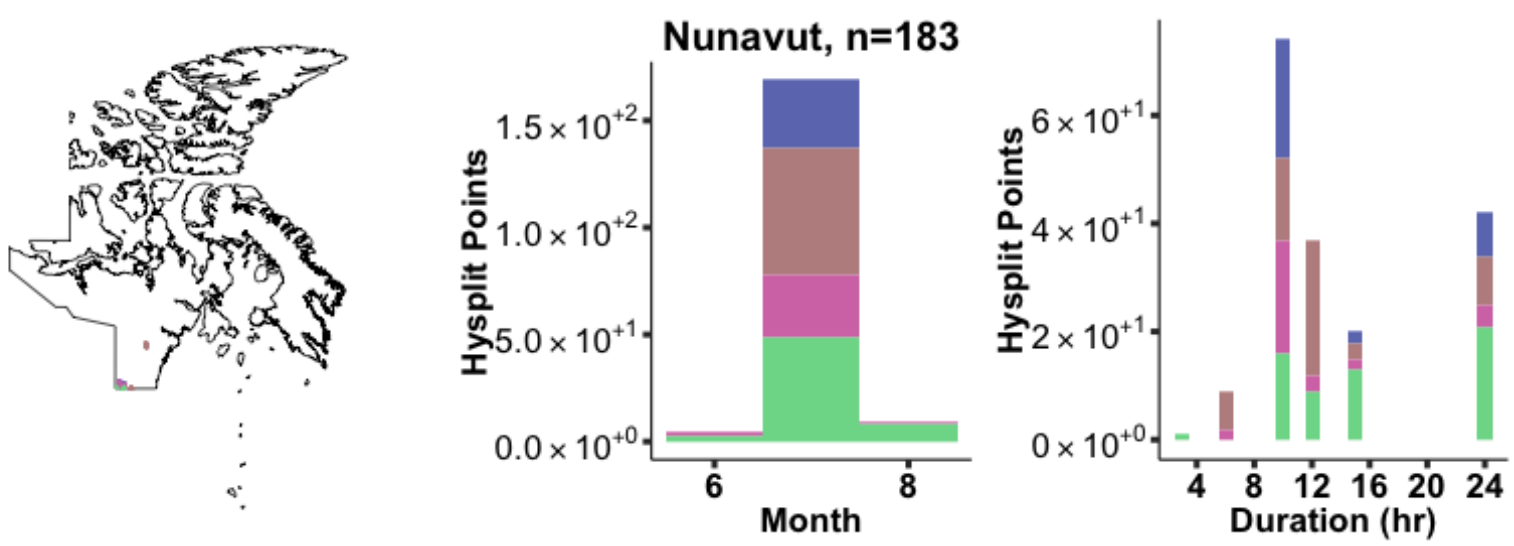

(o)

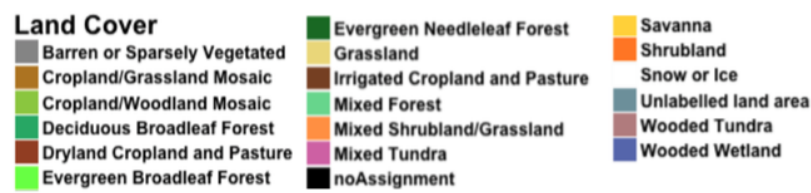



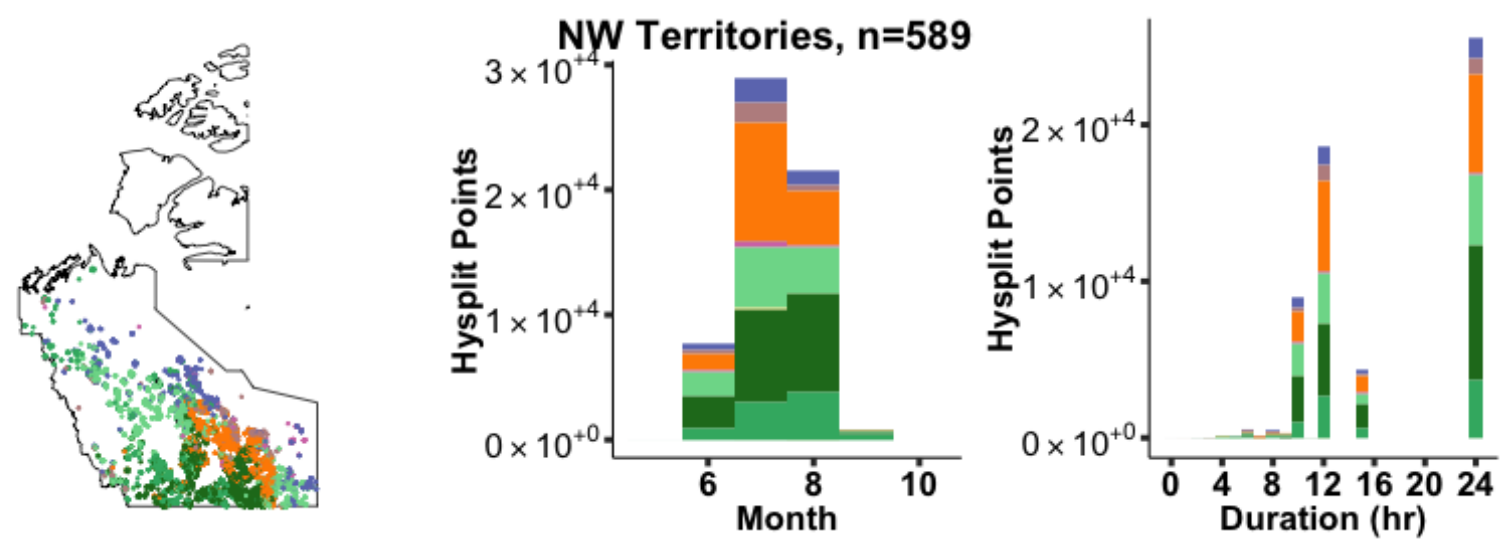

(p)
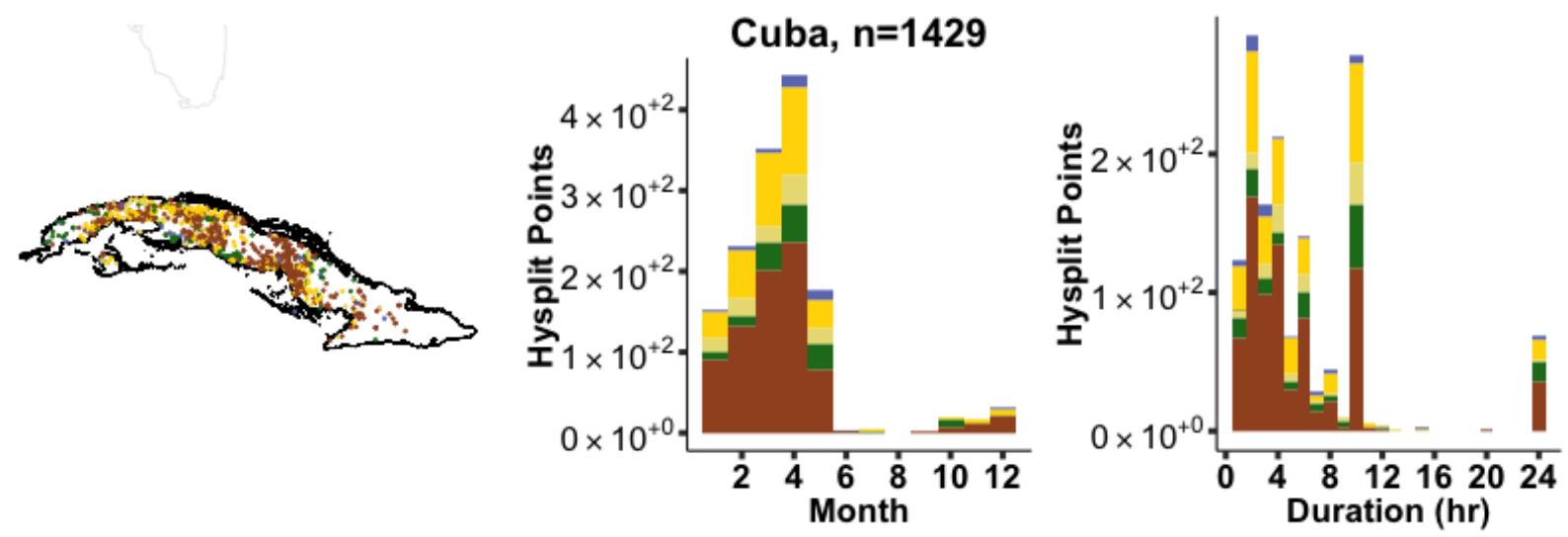

(q)
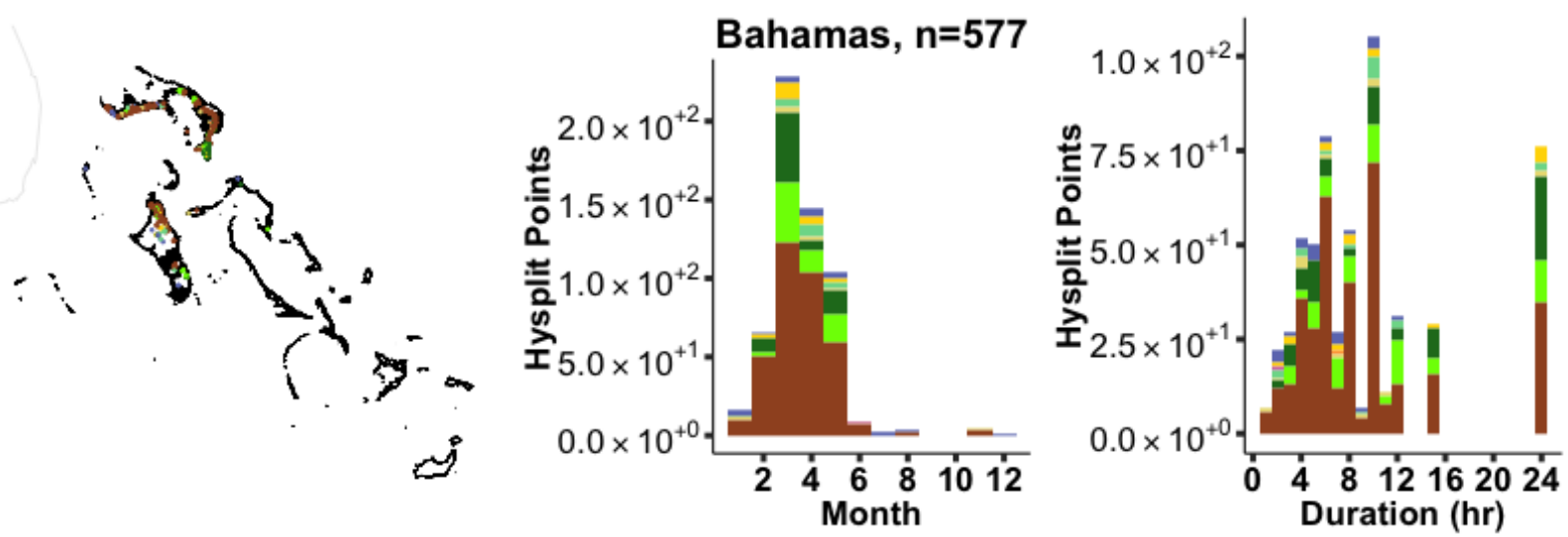

(r)

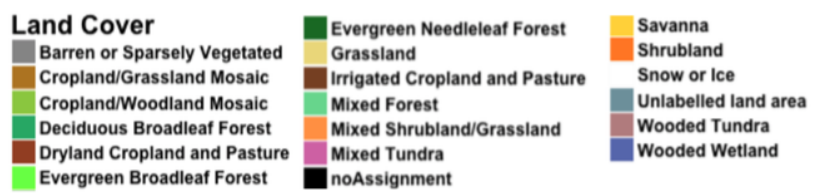

Figure S1: HYSPLIT Points locations and land cover classification represented by color (left), total number of occurrence by month and land cover classification (middle), duration and land cover classification (right). 


\section{S3 Overlapping trajectories with HMS smoke plumes:}

HMS smoke plumes are analyzed using visible satellite imagery. During the summer months most latitudes of North America experience daylight hours that span two different dates in UTC time. For example, on the summer solstice (June 20) in Seattle (47 degrees North) the sun sets at approximately 9:11 PM local time (PDT) which is 04:11 UTC June 21. However, operationally HMS stores daily smoke plume data for a single date relative to North America, though technically these files contain smoke plumes from two different UTC dates. In order to make the daily overlap analysis more relevant to the daylight hours over North America (when the smoke is observed), our overlap analysis shifted HYSPLIT trajectory times backwards by 6 hours. Had we not done this HYSPLIT Points with analyzed start times late in the afternoon could never overlap that dates smoke plumes since those trajectories occur after 24 UTC (next date). The adjustment allows more trajectories UTC dates to better overlap the daylight analysis date of the smoke plumes (including early morning). The results presented in Chapter 1 are highly insensitive to whether or not the 6 hour adjustment was applied. Previous versions of the figures and analysis prior to the 6 hour adjustment are nearly identical.

Validating the trajectories using only the first day of smoke would make it more likely that HYSPLIT points analyzed in the morning would overlap a plume than HYSPLIT points analyzed later in the day. Due to the visible daylight imagery limitations placed on analyzed smoke plumes, fires that start later in the day are less likely to overlap the matching dates smoke plumes than fires that start early in the day.

\section{S4 EDAS and GDAS smoke hours summaries for U.S. regions}

The biggest difference in smoke hours between EDAS and GDAS can be seen in Alaska, since only the southeast portion of the state is within the EDAS domain. Regions that receive smoke from high latitudes generally have more smoke-hours when the GDAS data is used (Mid Atlantic, Midwest, Northeast). Regardless of the meteorological dataset used for the trajectory calculations, the Northwest, Rocky Mountains, and Southwest are the largest smoke-source regions. They also have more smoke-hours over their regions when EDAS meteorology is used. This suggests that the higher-resolution EDAS meteorology results in more trajectories that overlap smoke plumes within the first 49 hours than trajectories run with GDAS meteorology. Thus the consequence of using EDAS meteorology is for regions to contribute more smoke-hours within their own borders and fewer downwind.

Table S3: Summary of smoke hours produced by and over each U.S. region for each meteorology dataset. Numbers show June-September totals between 2007-2014.

\begin{tabular}{c|c|c|c|c} 
Region & GDAS Produced & EDAS Produced & GDAS Over & EDAS Over \\
\hline Alaska & $8,412,383$ & 2 & $4,785,421$ & 10,685 \\
Great Plains & 781,704 & 757,094 & $12,382,290$ & $10,539,018$ \\
Mid Atlantic & 115,583 & 108,265 & 563,442 & 497,545 \\
Midwest & 143,343 & 145,691 & $6,684,312$ & $5,282,670$ \\
Northeast & 6,723 & 8,784 & 782,790 & 541,174 \\
Northwest & $29,360,026$ & $29,120,925$ & $12,083,168$ & $12,890,475$ \\
Rocky Mt. & $14,252,104$ & $13,703,437$ & $18,066,760$ & $19,064,474$ \\
Southeast & $2,553,898$ & $2,378,645$ & $1,799,372$ & $1,745,907$ \\
Southern Plains & $1,286,888$ & $1,296,988$ & $3,206,060$ & $3,437,671$ \\
Southwest & $28,552,926$ & $28,255,271$ & $10,069,858$ & $10,084,839$
\end{tabular}

\section{S5 Smoke hour false positives}

Our intent is for smoke hours to represent the advection of smoke; however, trajectory points can overlap smoke plumes that are not associated with the correct fires, and this creates smoke hours that are false positives. There are a number of possible scenarios that could lead to a smoke-hour false positive; to illustrate this we will highlight two possible scenarios here. 1) Trajectory points could be validated on the 
first two days when they overlap a smoke plume that has been advected from upwind. These trajectory points could then travel with that existing smoke plume and be incorrectly classified as smoke hours. This scenario does not necessarily mean that the fire associated with the trajectory does not produce smoke. It is possible that the trajectory misses the plume created by its associated HYSPLIT point due to being initialized at the wrong injection height. 2) Trajectory points could overlap smoke for the first day, then no smoke for a couple of days, then overlap an unrelated smoke plume very far downwind. Both of these types of false positives have been observed in developing our definition for smoke hours.

Currently the best way we have of identifying false-positive smoke hours is sorting trajectories into smaller aggregates (individual years and seasons) and observing the heat maps associated with these subsets of trajectories. The second type of false positive described above would be visible in these types of maps as disconnected smoke hours. The long-range transport of smoke hours originating in the Northwest during winter months provides ideal conditions to test the methods described in Sect 5.2. In winter months there are fewer and smaller fires and fewer smoke plumes analyzed by HMS. Additionally, fires that occur in the winter have lower smoke-injection altitudes on average compared to their summer counterparts (Val Martin et al., 2010; Paugam et al., 2016). All of these factors will tend to reduce the long-range transport of smoke during winter months. The Northwest has very-little fire activity for the first three months of the year. In contrast, January, February, and March have a significant amount of local fire activity in the Southeast as indicated by the number of HYSPLIT points for these months. These conditions create an ideal environment for trajectories that originate in the Northwest to travel to the Southeast without advecting any smoke and create false positive smoke hours. When we plot the heat map for the Northwest for these months we see two disconnected hot spots (Fig. S2), which almost certainly represent false positives far downwind. Figure S2 shows how the Northwest contributes smoke hours to the Northwest and Southeast without impacting the Rocky Mountain region. This strongly suggests that the smoke hours over the Southeast are false positives. During the summer there is very little local fire activity in the Southeast so it is likely this problem dominates the summer smoke hour transport climatologies shown in Fig. 13 of the manuscript. This type of evidence for false positive smoke hours is not apparent in summertime data; however, the very large smoke plumes analyzed during the summer may not allow for disconnection. Even for individual-year heat maps, we do not observe disconnected areas of smoke impact far downwind of source regions. Winter smoke-hour transport figures for all regions are shown in Fig. S7.

HMS analysts observe that fires in the Great Plains, Southern Plains, and Midwest, generally produce short duration smoke plumes that quickly dissipate. It is unusual for smoke produced in these regions to persist long enough to reach areas of Northern Canada or the Canadian Maritimes. Thus the long range transport smoke hour impact from these regions shown in manuscript Fig. S6 may be examples of trajectories overlapping HMS smoke plumes that originated in other source regions. 


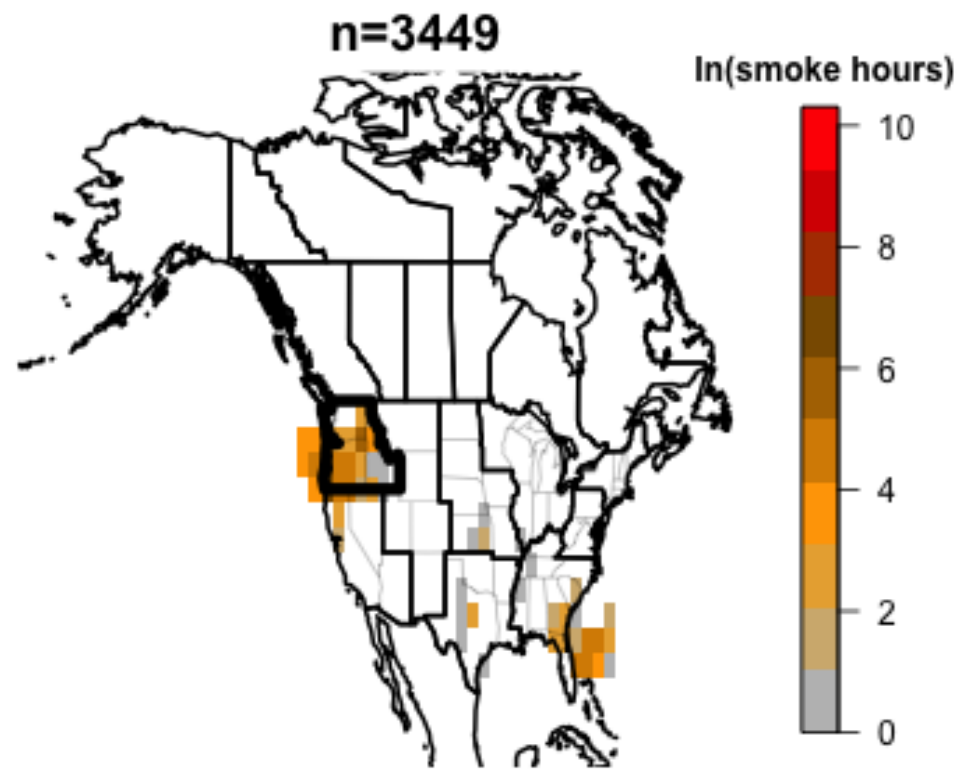

Figure S2: Total number of smoke hours produced by the Northwest region for months January-March between 2007 and 2014 using GDAS1 meteorology.

\section{S6 Smoke hour transport figures for non-CONUS regions:}

Here we present the GDAS1 smoke hour transport figures (similar to Fig 11) for regions outside of CONUS. The U.S Islands and Cuba are not included due to limited smoke-hours over these regions. 

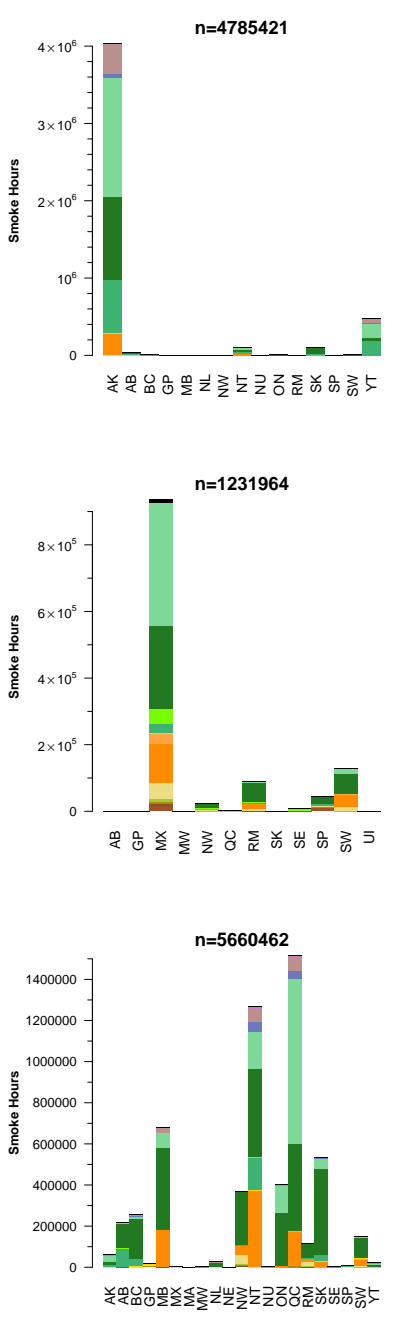
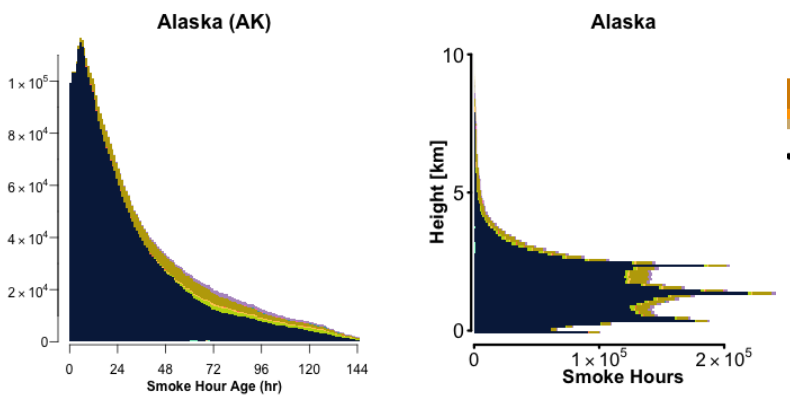

(a)
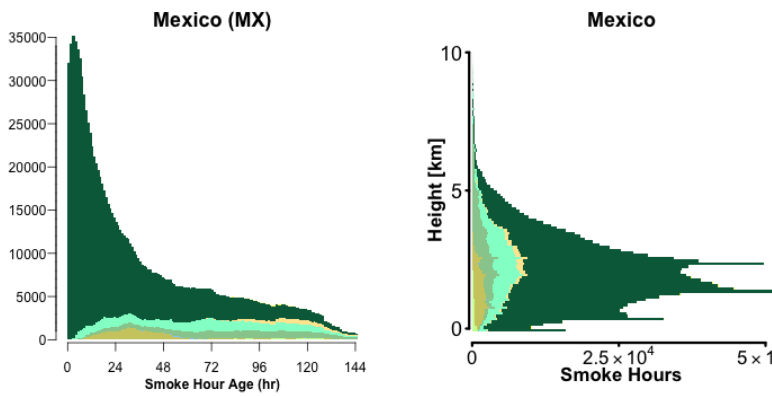

(b)
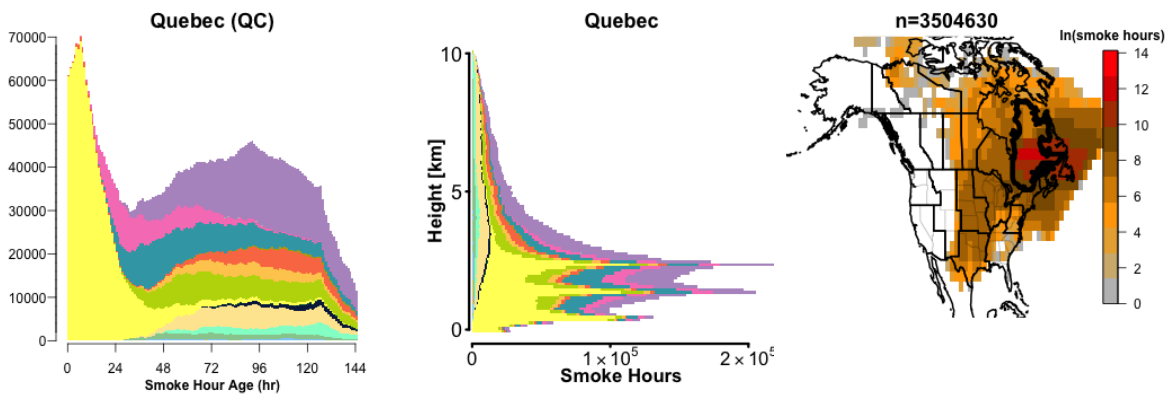

(c)

$\begin{array}{lllll}\text { Region } & \text { GP } \square \text { MX } \square \text { BC } \square \text { NU } \\ \square \text { NE } & \text { RM } \square \text { QC } \square \text { NB } \square \text { NT } \\ \square \text { MA } \square \text { SW } \square \text { NS } \square \text { PE } \square \text { CU } \\ \square \text { SE } \square \text { NW } \square \text { SK } \square \text { YT } \square \text { BS } \\ \square \text { MW } \square \text { AK } \square \text { AB } \square \text { MB } & \\ \square \text { SP } & \text { Ul } \square \text { NL } \square \text { ON }\end{array}$



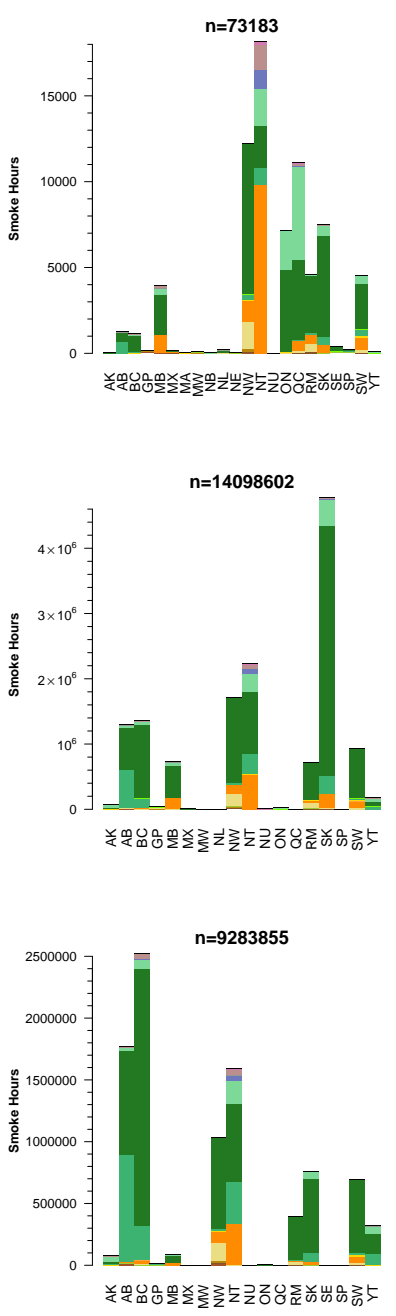
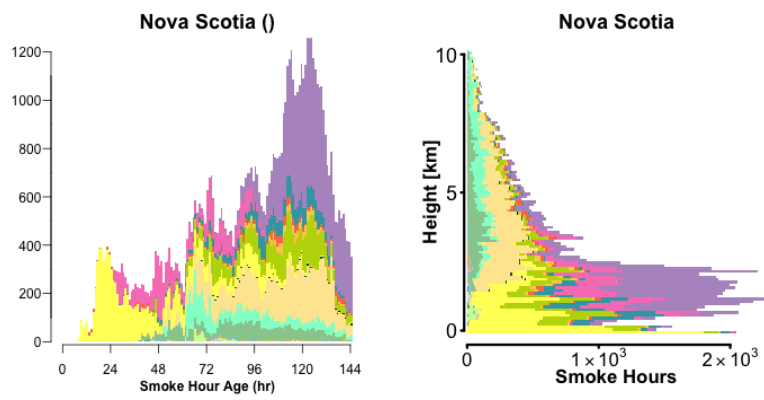

(d)
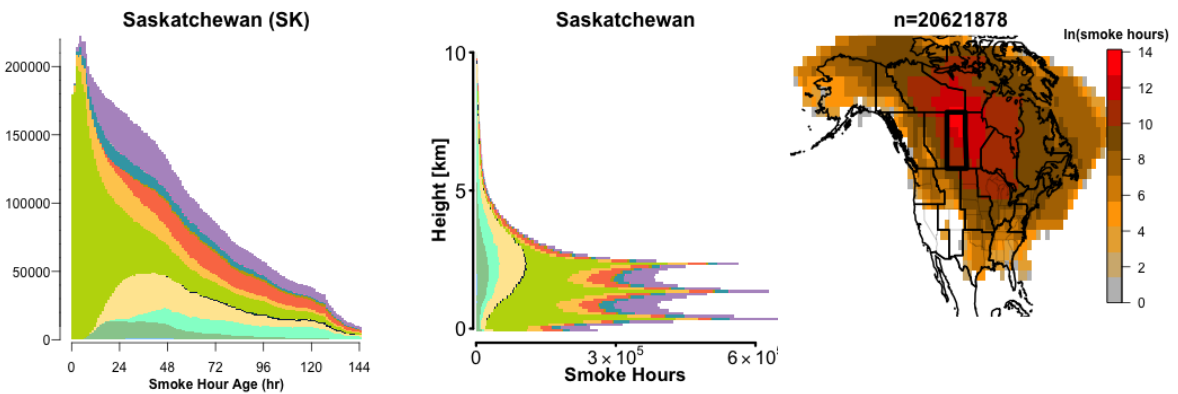

(e)
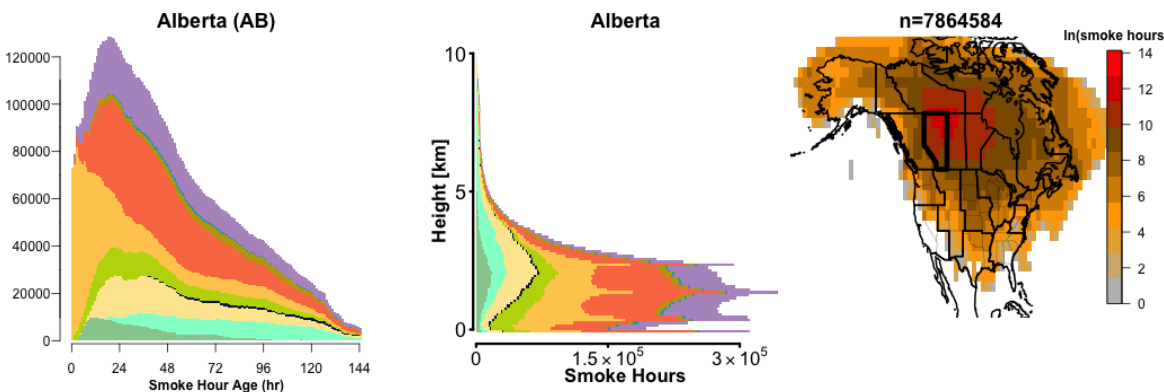

(f)

$\begin{array}{llllll}\text { Region } & \text { GP } \square \text { MX } \square \text { BC } \square \text { NU } \\ \square \text { NE } & \text { RM } \square \text { QC } \square \text { NB } \square \text { NT } \\ \square \text { MA } \square \text { SW } \square \text { NS } \square \text { PE } \square \text { CU } \\ \square \text { SE } \square \text { NW } \square \text { SK } \square \text { YT } \square \text { BS } \\ \square \text { MW } \square \text { AK } \square \text { AB } \square \text { MB } \\ \square \text { SP } \square \text { UI } \square \text { NL } \square \text { ON }\end{array}$



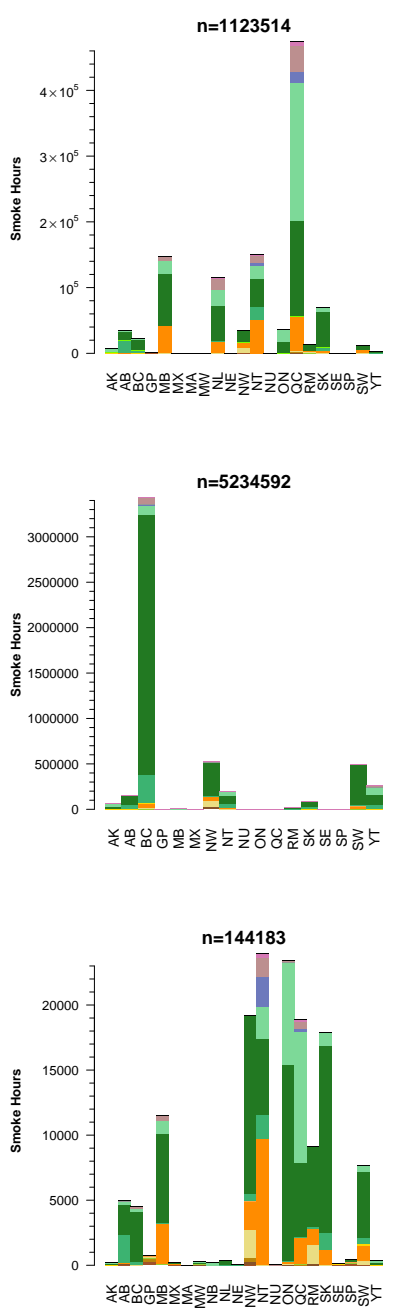
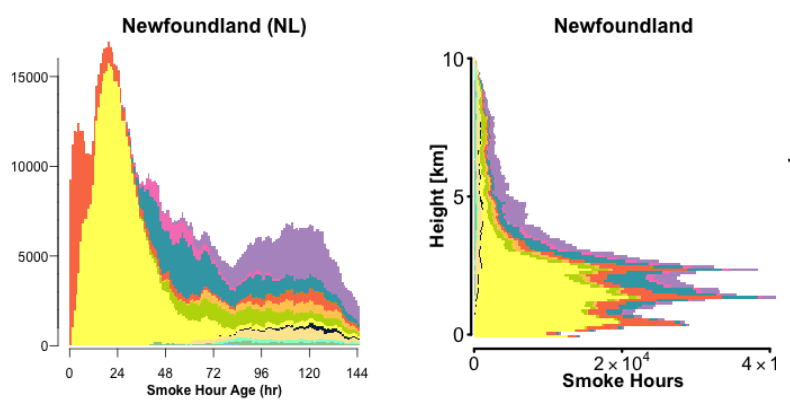

(g)
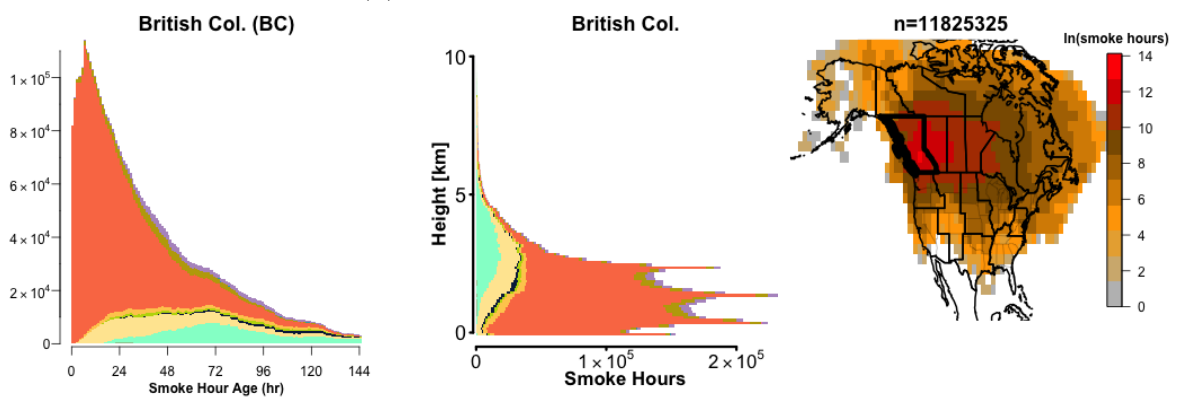

(h)
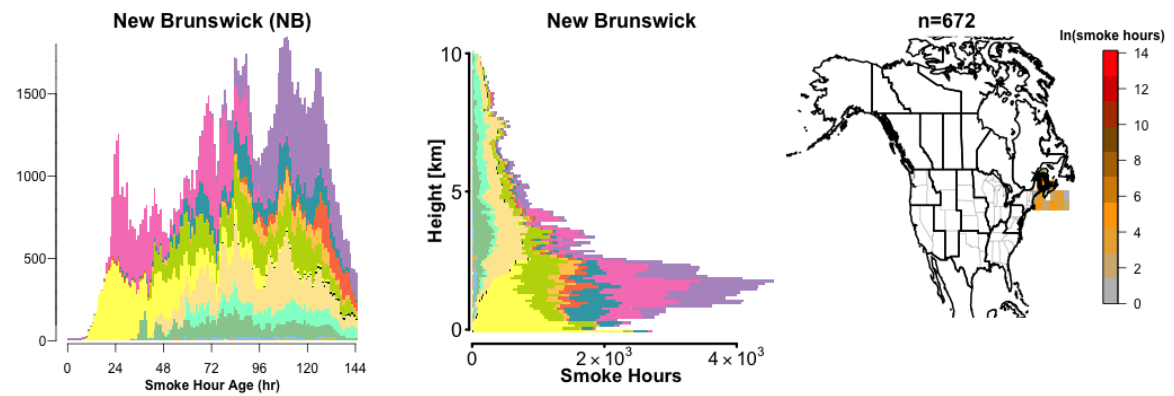

(i)

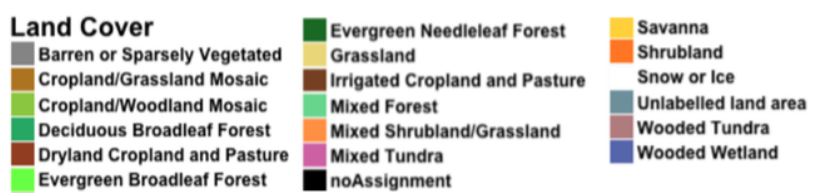

$\begin{array}{lllll}\text { Region } & \text { GP } \square \text { MX } \square \text { BC } \square \text { NU } \\ \square \text { NE } & \text { RM } \square \text { QC } \square \text { NB } \square \text { NT } \\ \square \text { MA } \square \text { SW } \square \text { NS } \square \text { PE } \square \text { CU } \\ \square \text { SE } \square \text { NW } \square \text { SK } \square \text { YT } \square \text { BS } \\ \square \text { MW } \square \text { AK } \square \text { AB } \square \text { MB } & \\ \square \text { SP } \square \text { UI } \square \text { NL } \square \text { ON } & \end{array}$



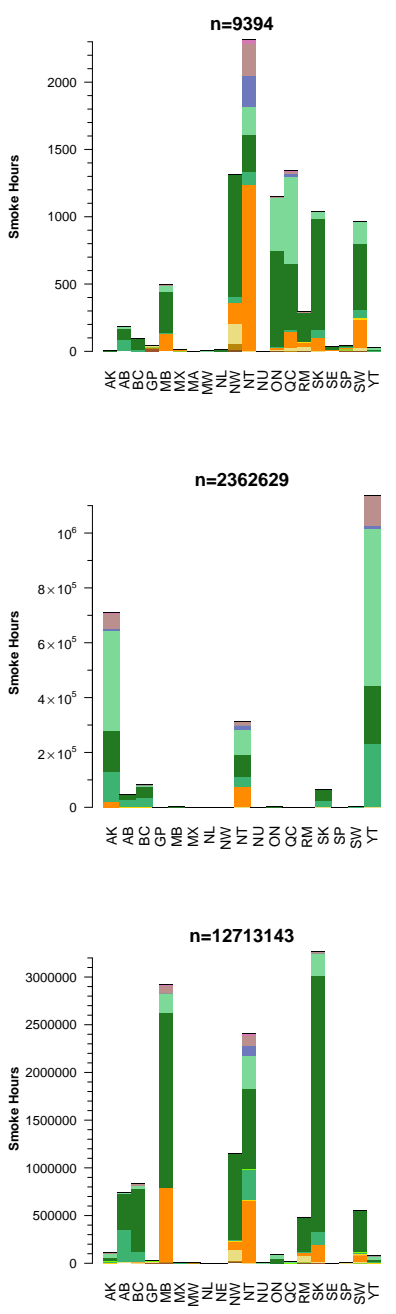
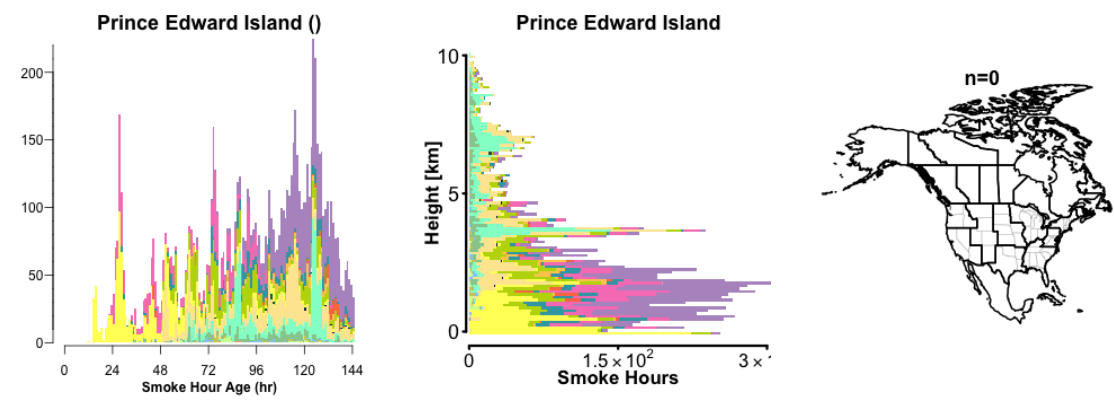

(j)
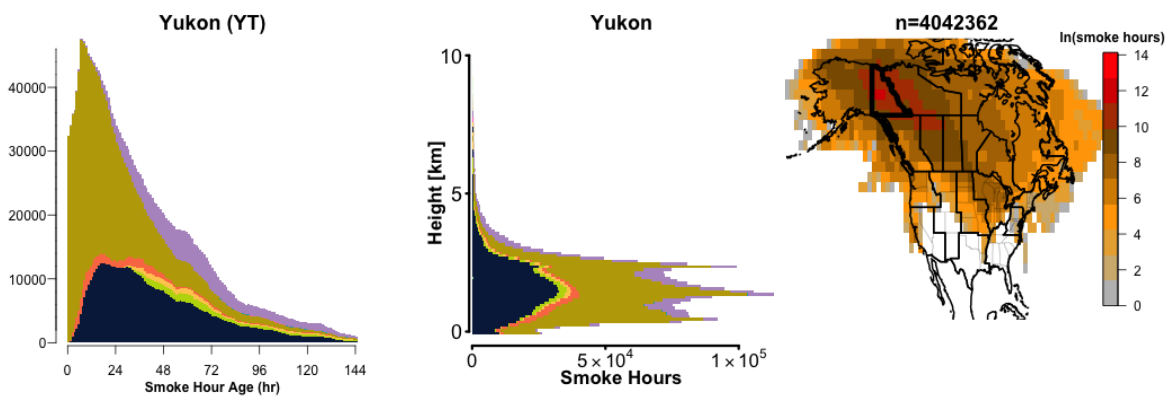

(k)
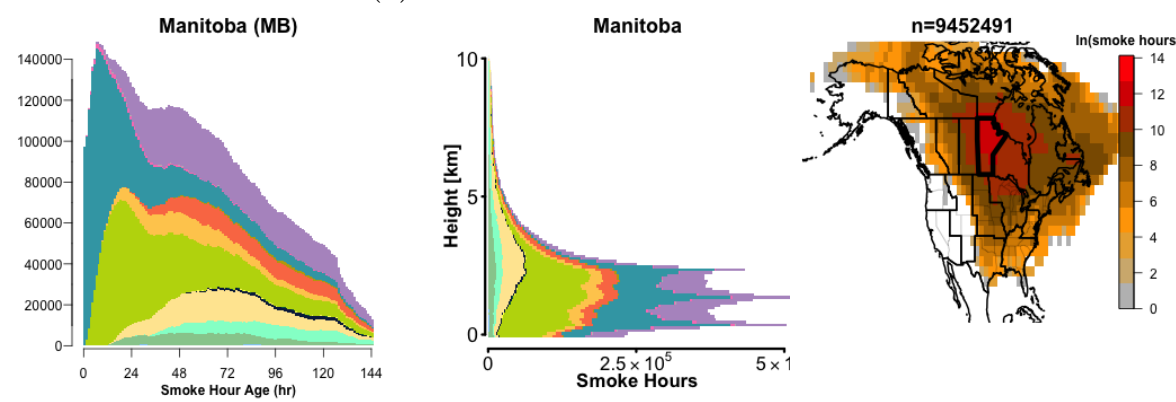

(1)

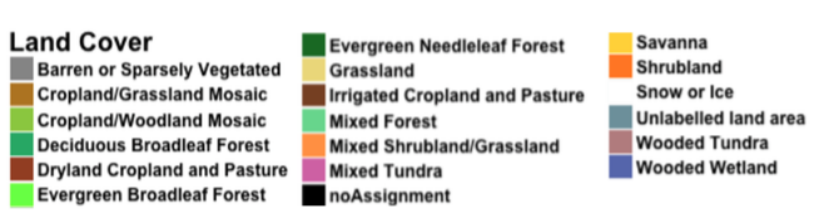

$\begin{array}{llllll}\text { Region } & \text { GP } \square \text { MX } \square \text { BC } \square \text { NU } \\ \square \text { NE } & \text { RM } \square \text { QC } \square \text { NB } \square \text { NT } \\ \square \text { MA } \square \text { SW } \square \text { NS } \square \text { PE } \square \text { CU } \\ \square \text { SE } \square \text { NW } \square \text { SK } \square \text { YT } \square \text { BS } \\ \square \text { MW } \square \text { AK } \square \text { AB } \square \text { MB } \\ \square \text { SP } \square \text { UI } \square \text { NL } \square \text { ON }\end{array}$



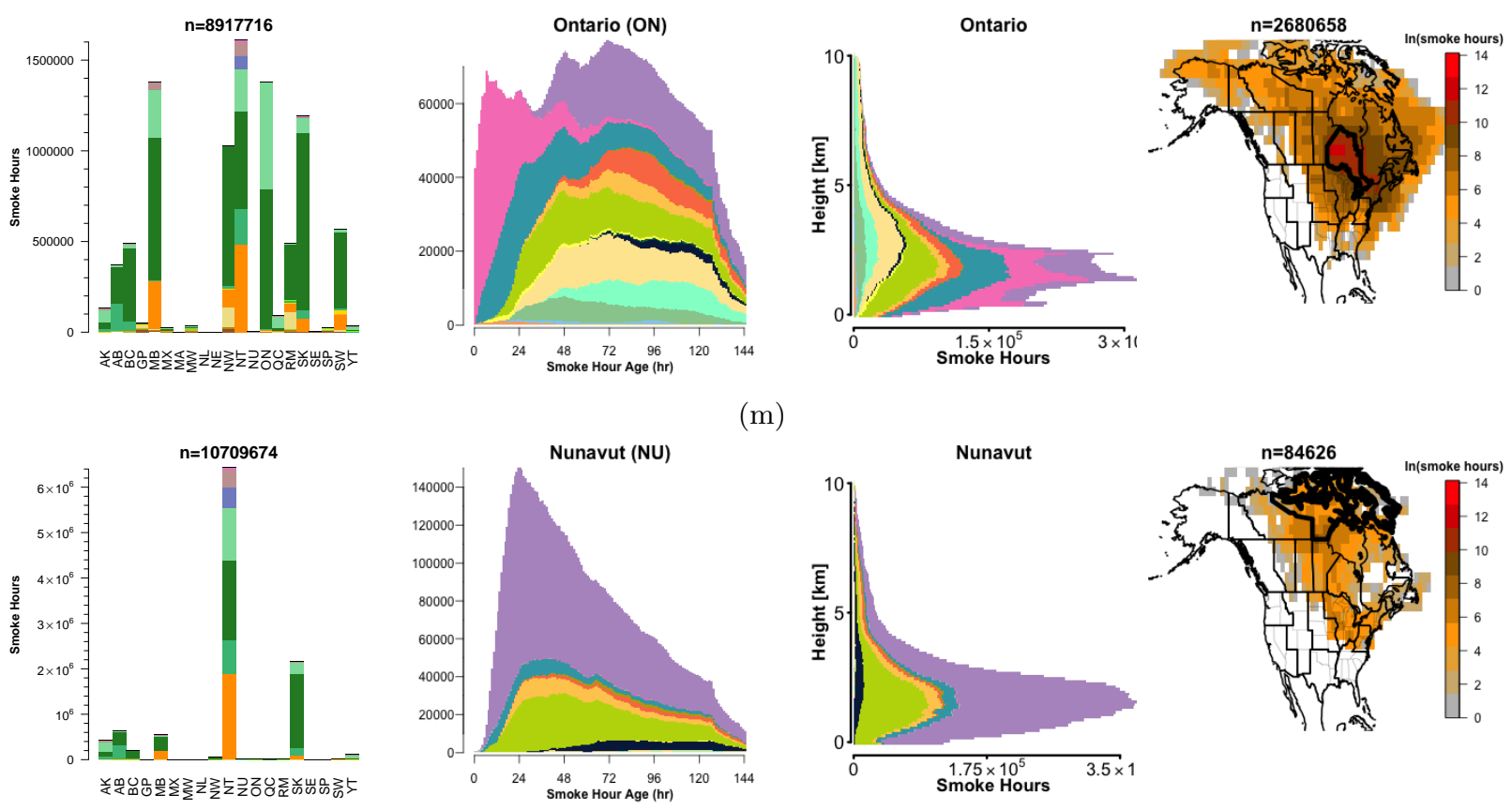

(n)

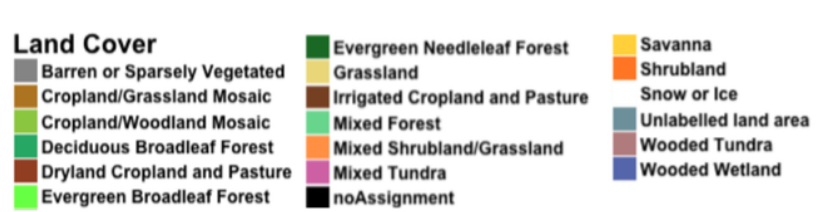

$\begin{array}{llllll}\text { Region } & \text { GP } \square \text { MX } \square \text { BC } \square \text { NU } \\ \square \text { NE } & \text { RM } \square \text { QC } \square \text { NB } \square \text { NT } \\ \square \text { MA } \square \text { SW } \square \text { NS } \square \text { PE } \square \text { CU } \\ \square \text { SE } \square \text { NW } \square \text { SK } \square \text { YT } \square \text { BS } \\ \square \text { MW } \square \text { AK } \square \text { AB } \square \text { MB } \\ \square \text { SP } \square \text { UI } \square \text { NL } \square \text { ON }\end{array}$



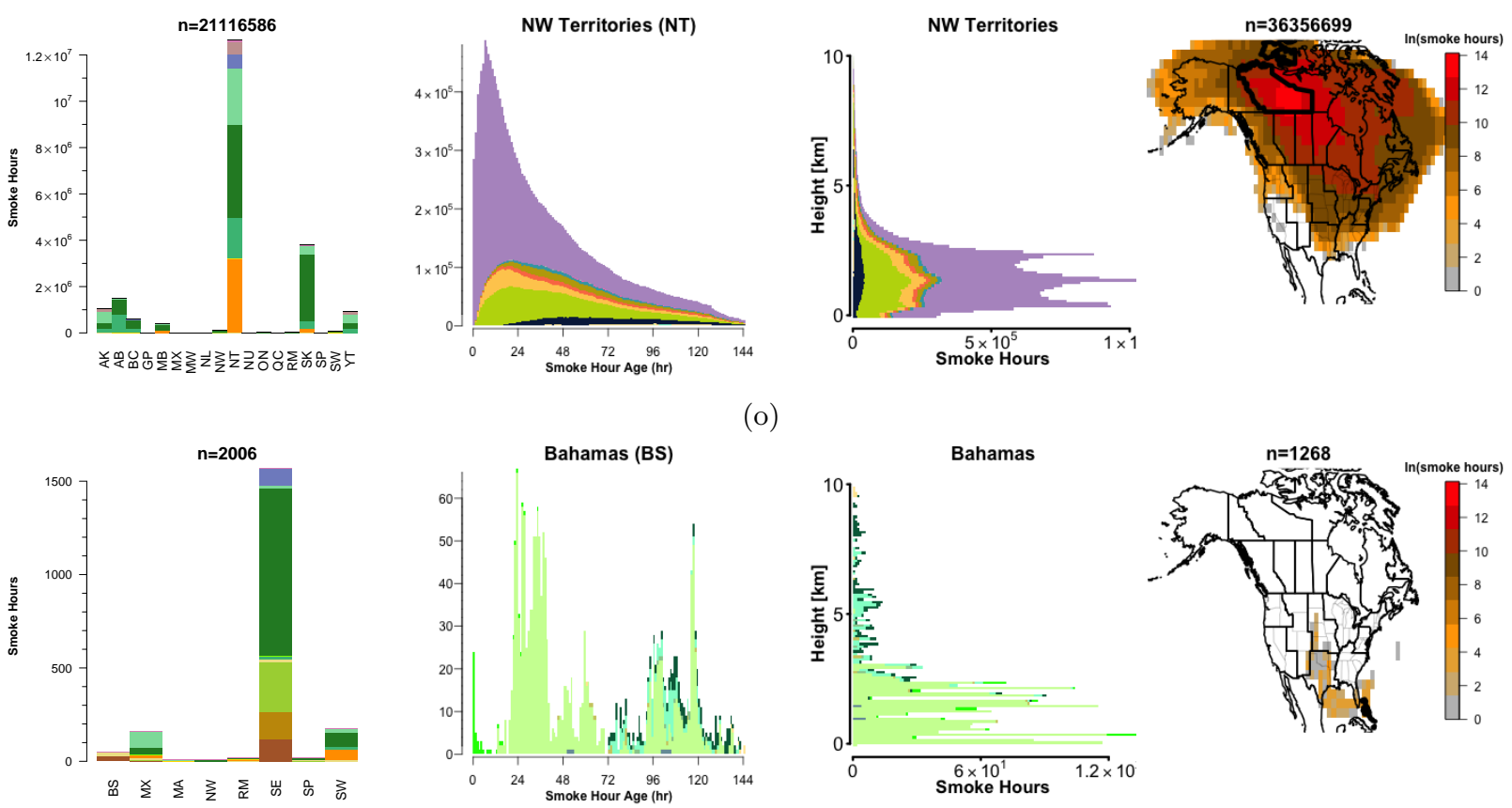

(p)
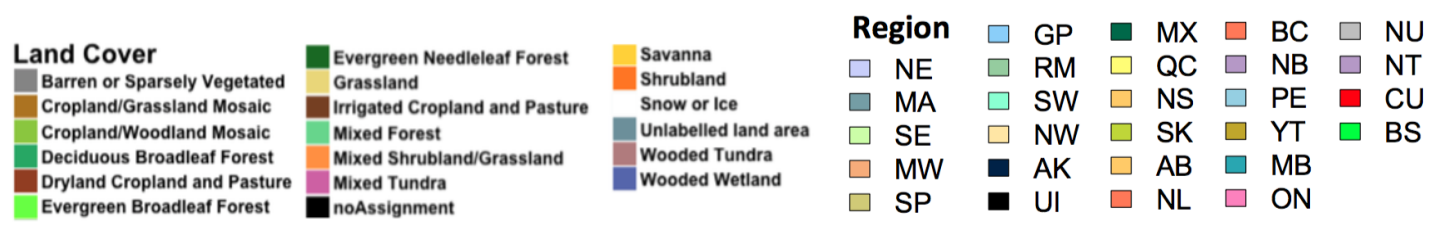

Figure S3: June-September 2007-2014 regional smoke hour transport summaries for non-CONUS regions. Column 1 shows the number of smoke hours in the region by source region and land cover classification. Only source regions with non-zero smoke hour contributions are shown. Column 2 shows the distribution of smoke hour age segregated by source region using the colors from manuscript Fig. 6 . Column 3 shows the distribution of smoke hour height segregated by source region using the colors from manuscript Fig. 6 . Column 4 shows the count of smoke hours produced by a region on a $2^{\circ} \times 2^{\circ}$ degree grid with consistent color bar for all regions. The grid spans $18-180^{\circ} \mathrm{W}$ and $18-90^{\circ} \mathrm{N}$, a domain covering all five sectors where HMS analyzes smoke plumes (only a subset plotted). Shaded values are the natural logarithm of the number of smoke hours in each grid cell. All figures were generated using GDAS1 meteorology.

\section{S7 EDAS meteorology versions of manuscript figures:}

Figures 10 \& 11 of the manuscript is driven by GDAS1 meteorology data. This section provides these figures when EDAS40 meteorology data is used to run HYSPLIT trajectories. 
Total Smoke Hours Produced

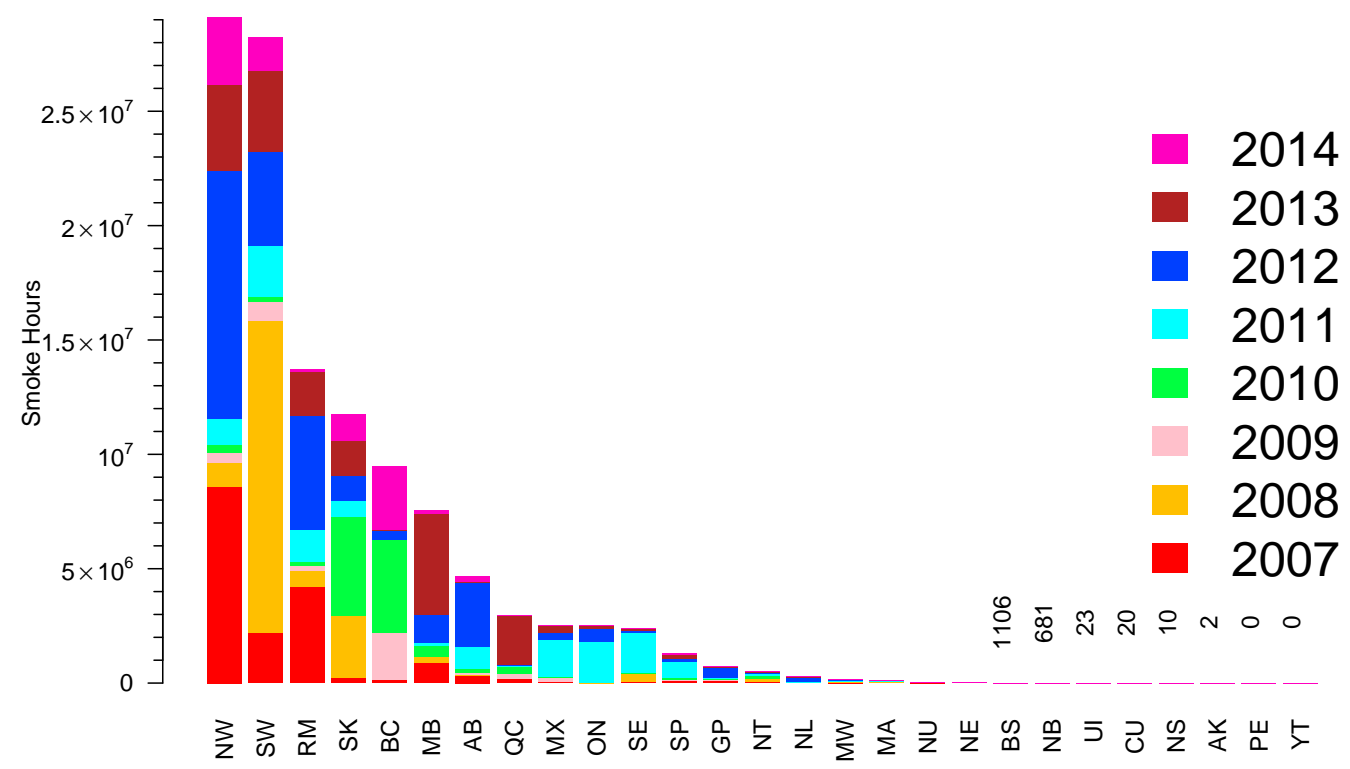

Figure S4: Total number of smoke hours produced (anywhere) by each region for months June-September between 2007 and 2014 using EDAS40 meteorology.

Total Smoke Hours Over Region

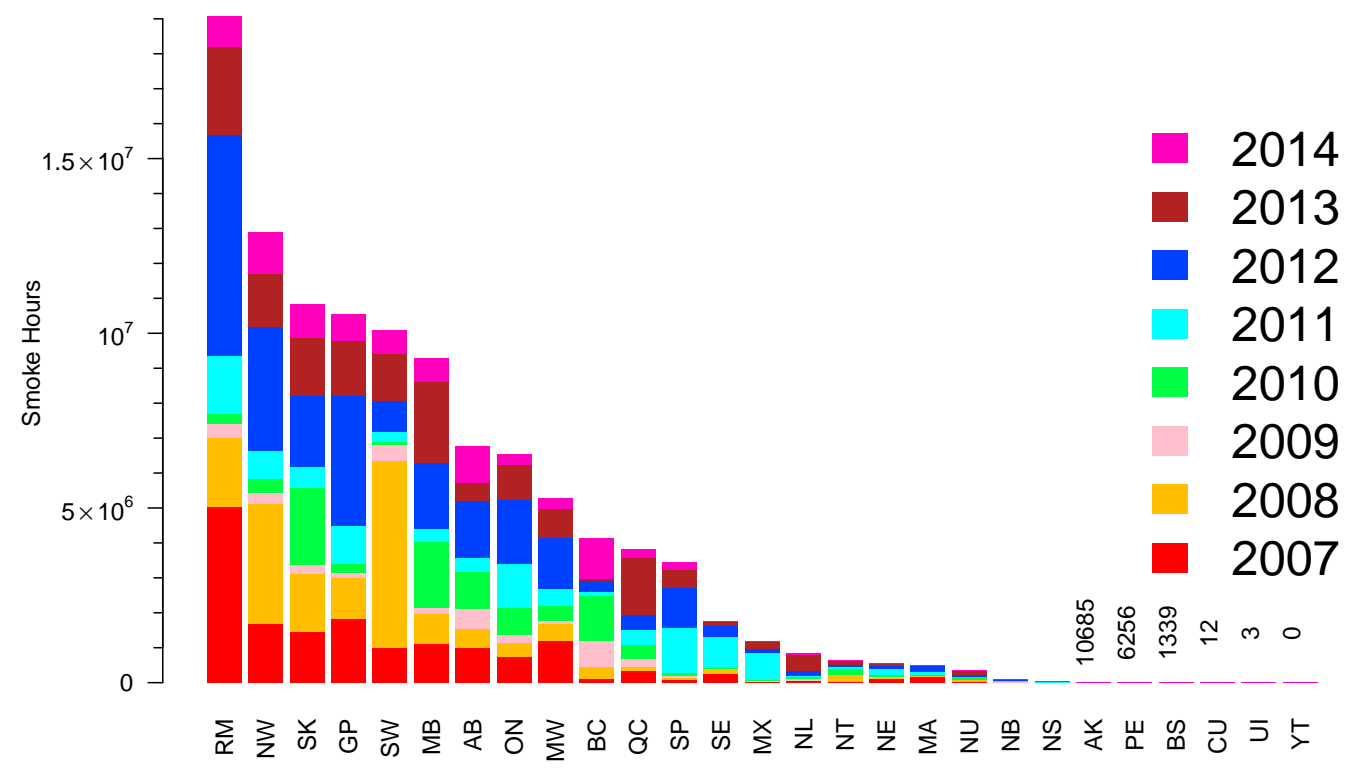

Figure S5: Total number of smoke hours over each region sorted from highest to lowest for months JuneSeptember between 2007 and 2014 using EDAS40 meteorology. 

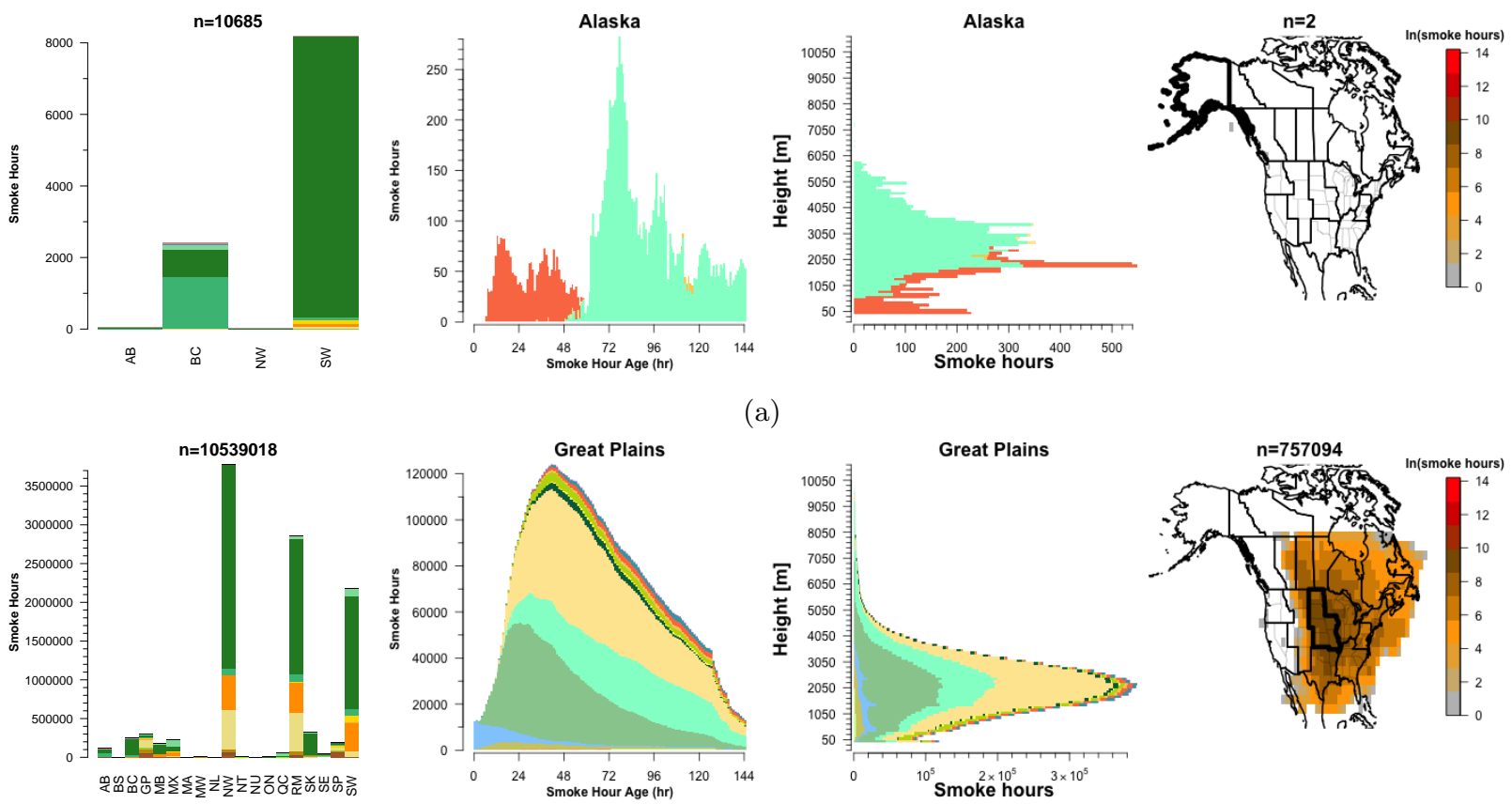

(a)
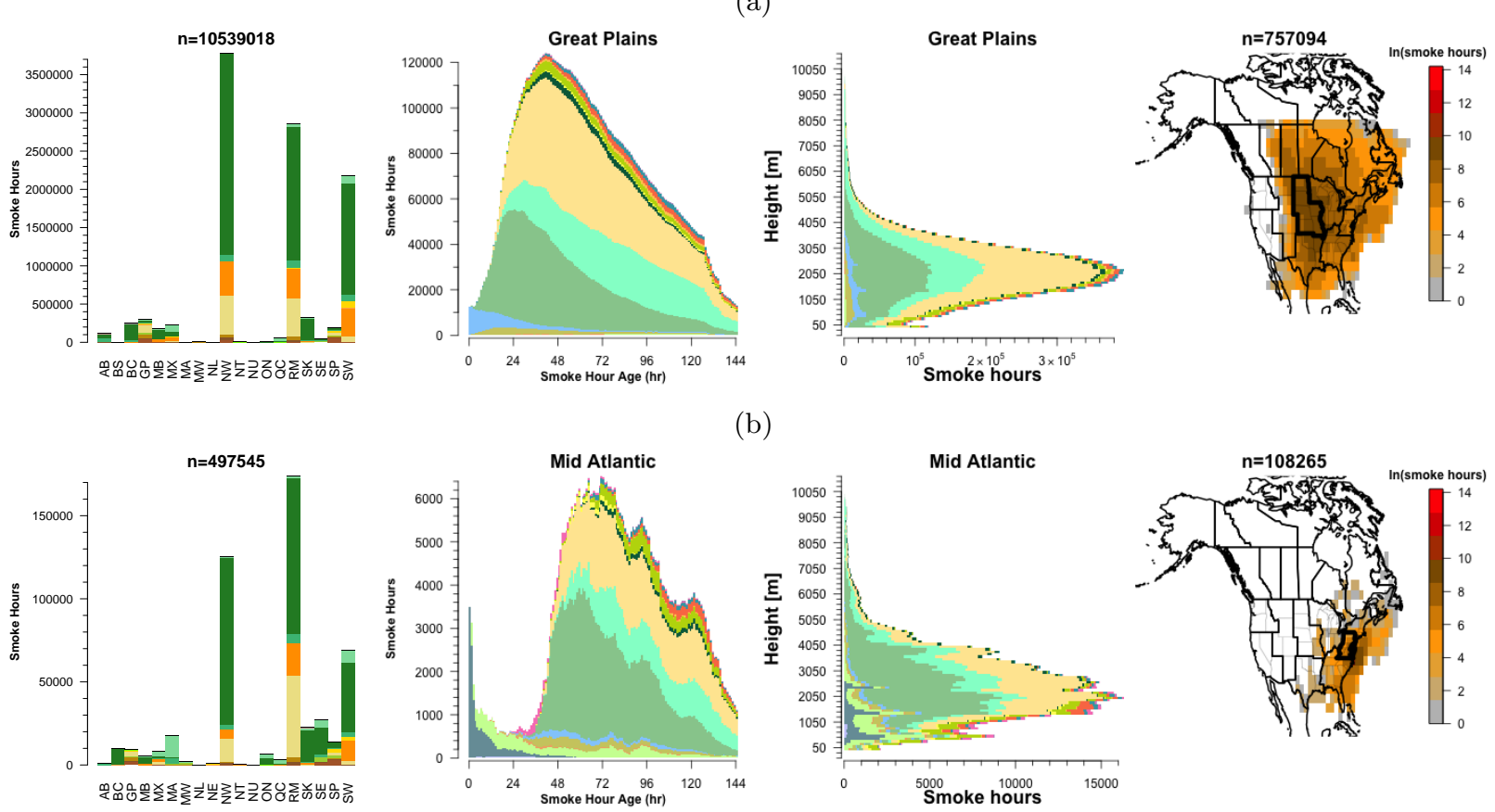

(b)

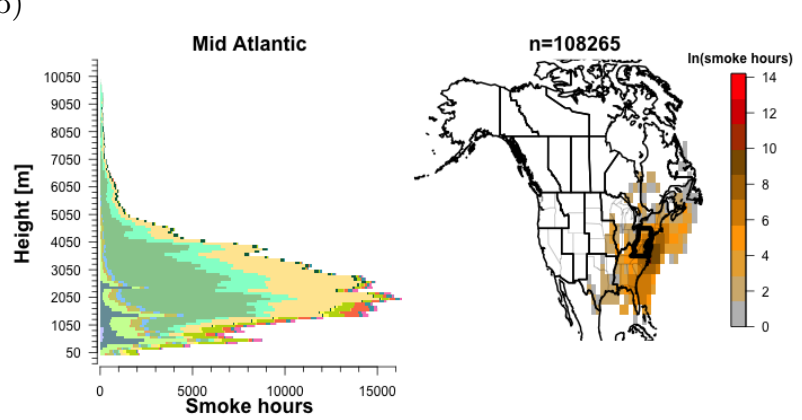

(c)

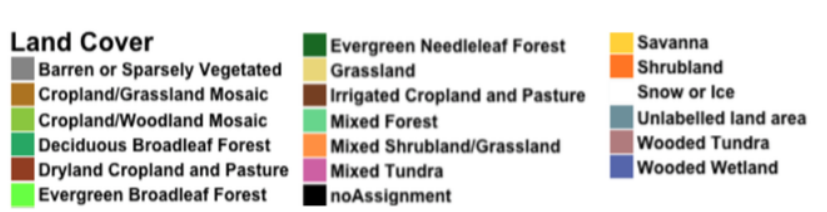

$\begin{array}{llllll}\text { Region } & \text { GP } \square \text { MX } \square \text { BC } \square \text { NU } \\ \square \text { NE } & \text { RM } \square \text { QC } \square \text { NB } \square \text { NT } \\ \square \text { MA } \square \text { SW } \square \text { NS } \square \text { PE } \square \text { CU } \\ \square \text { SE } \square \text { NW } \square \text { SK } \square \text { YT } \square \text { BS } \\ \square \text { MW } \square \text { AK } \square \text { AB } \square \text { MB } \\ \square \text { SP } \square \text { UI } \square \text { NL } \square \text { ON }\end{array}$



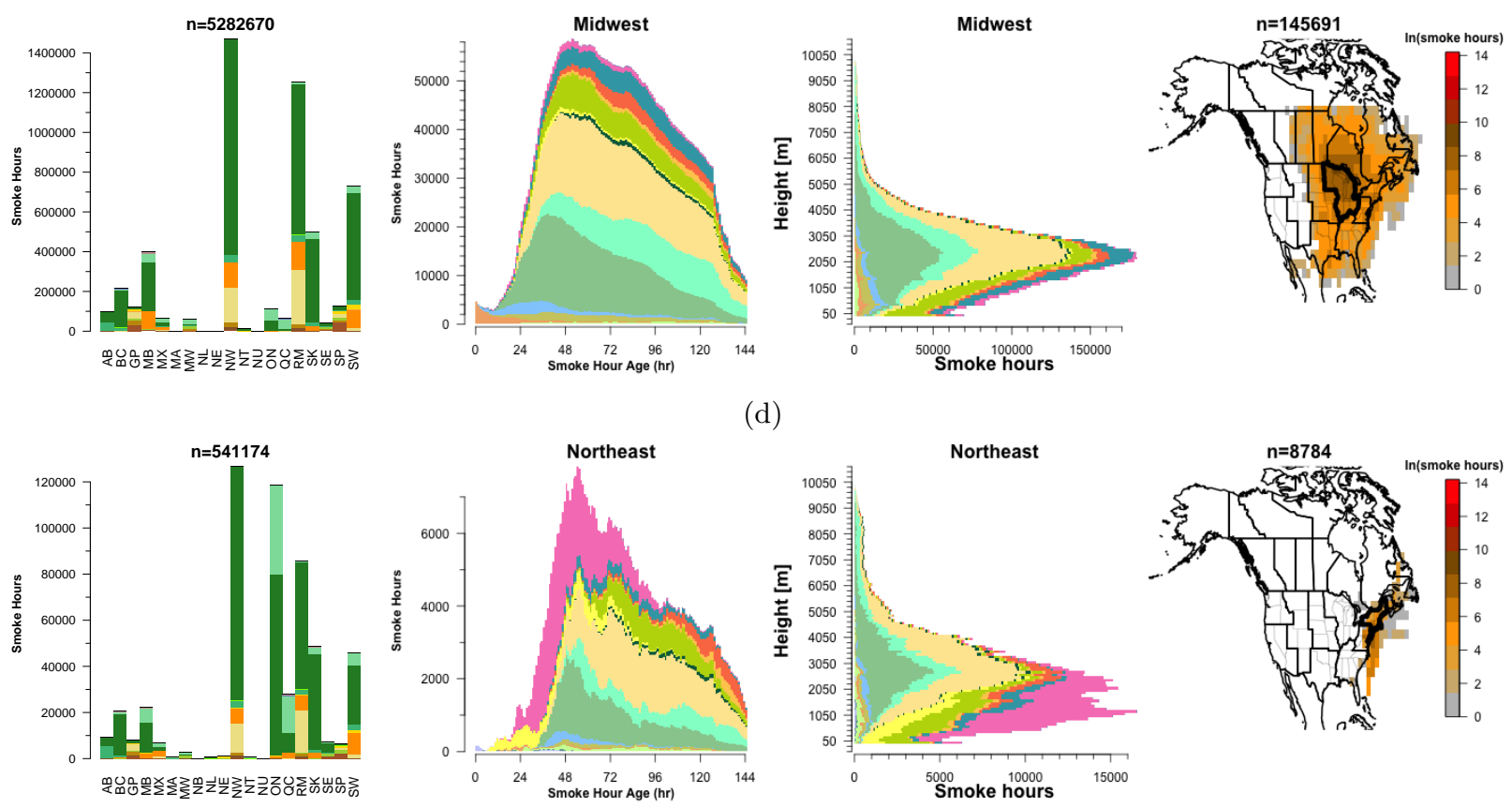

(d)
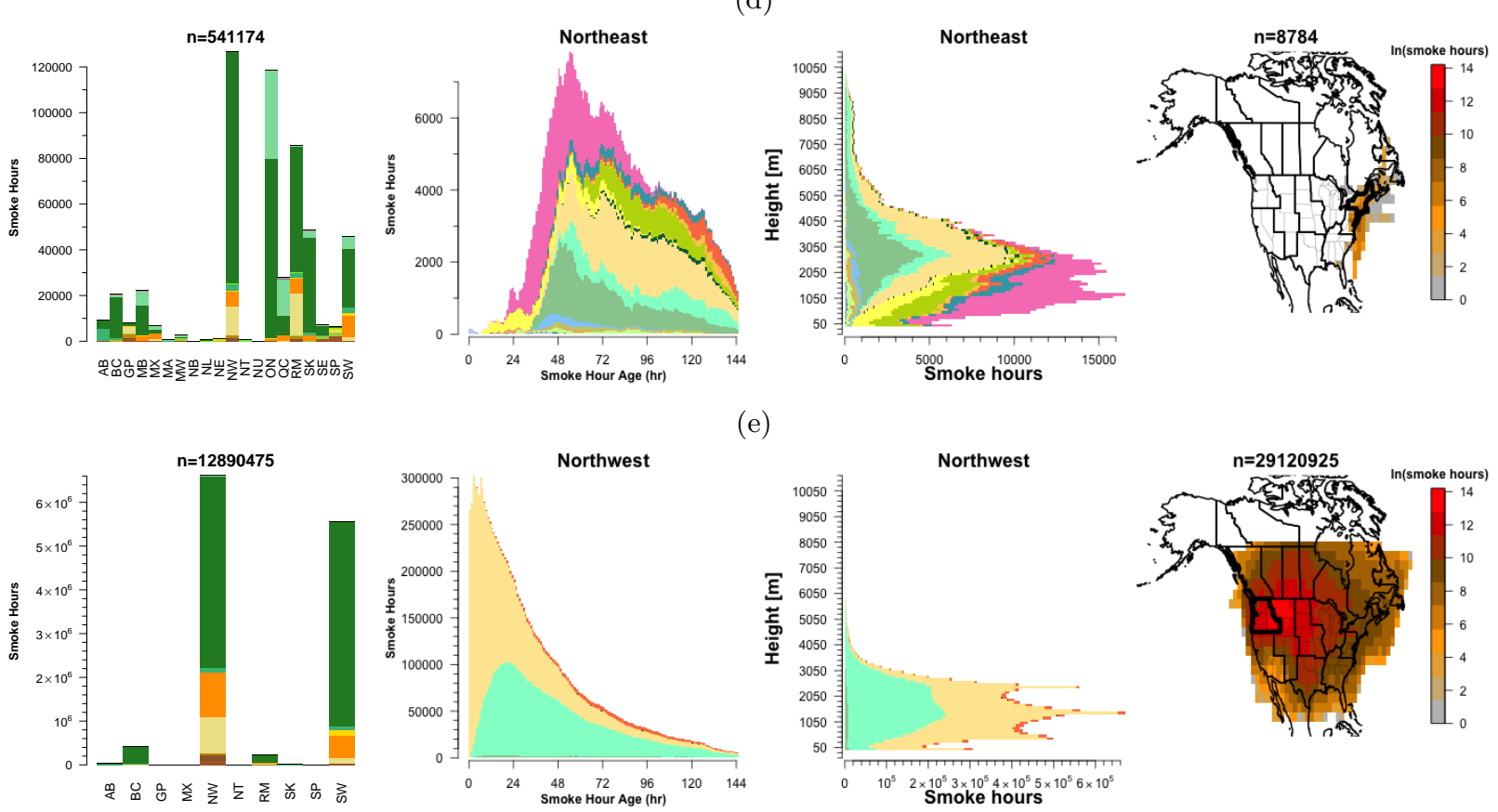

(e)
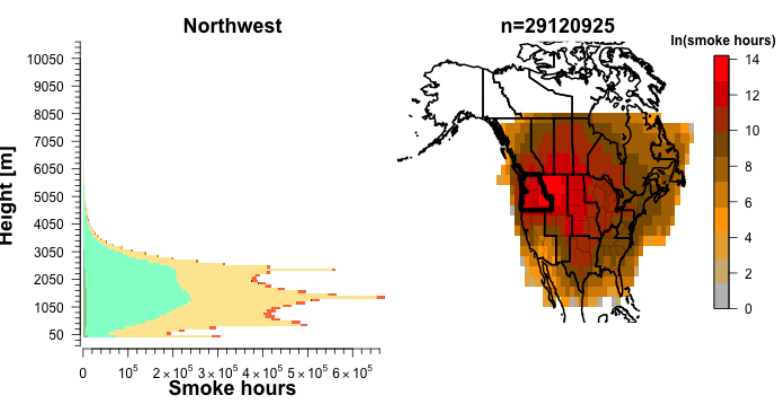

(f)

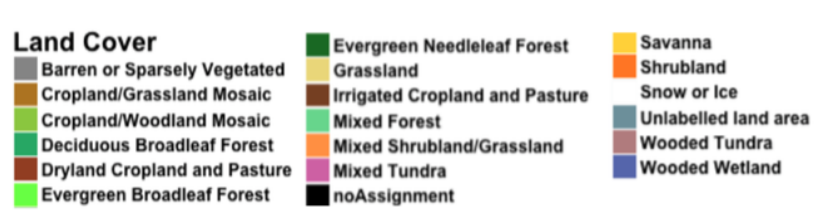

$\begin{array}{llllll}\text { Region } & \text { GP } \square \text { MX } \square \text { BC } \square \text { NU } \\ \square \text { NE } & \text { RM } \square \text { QC } \square \text { NB } \square \text { NT } \\ \square \text { MA } \square \text { SW } \square \text { NS } \square \text { PE } \square \text { CU } \\ \square \text { SE } \square \text { NW } \square \text { SK } \square \text { YT } \square \text { BS } \\ \square \text { MW } \square \text { AK } \square \text { AB } \square \text { MB } \\ \square \text { SP } \square \text { UI } \square \text { NL } \square \text { ON }\end{array}$



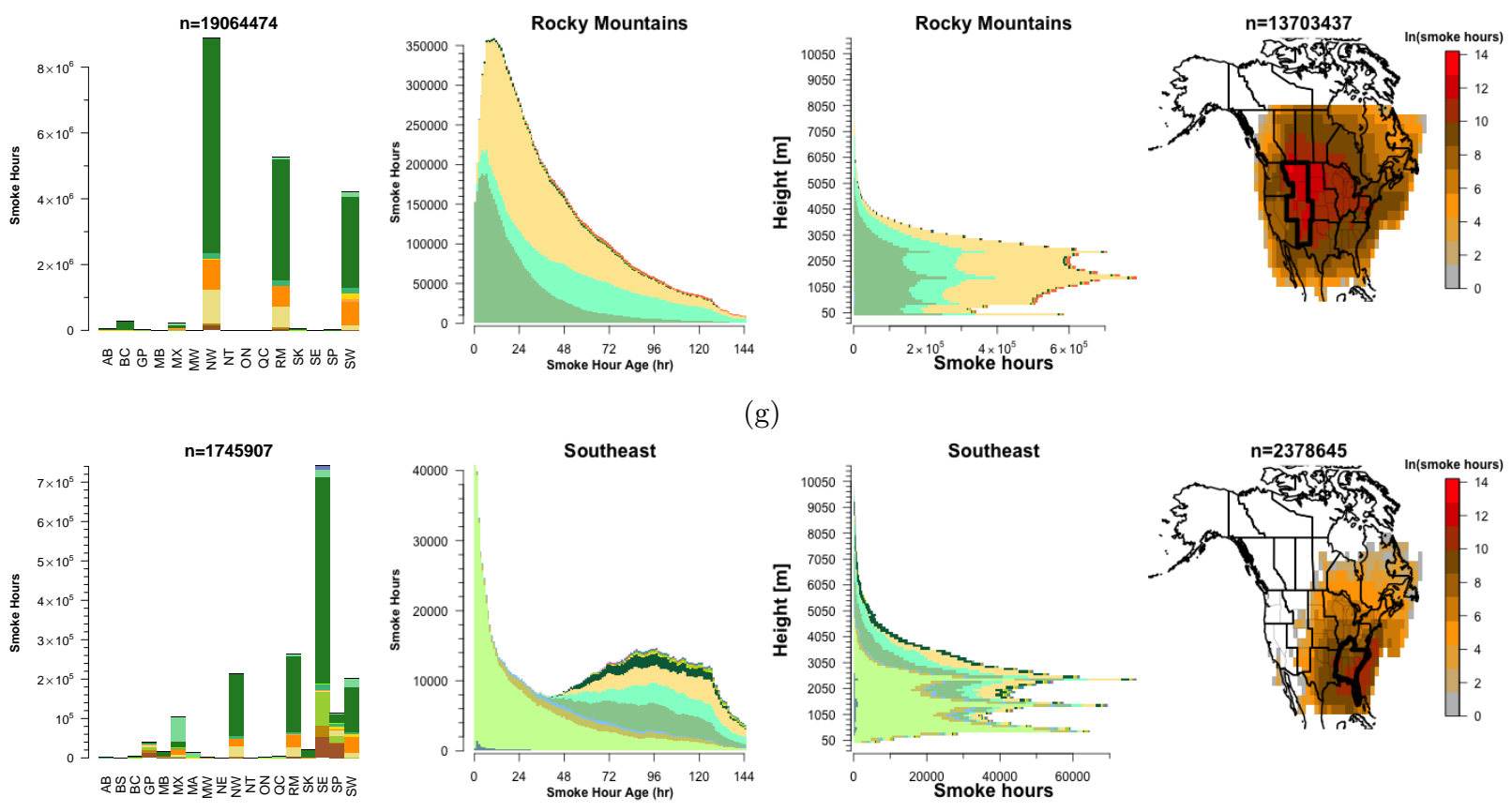

(g)
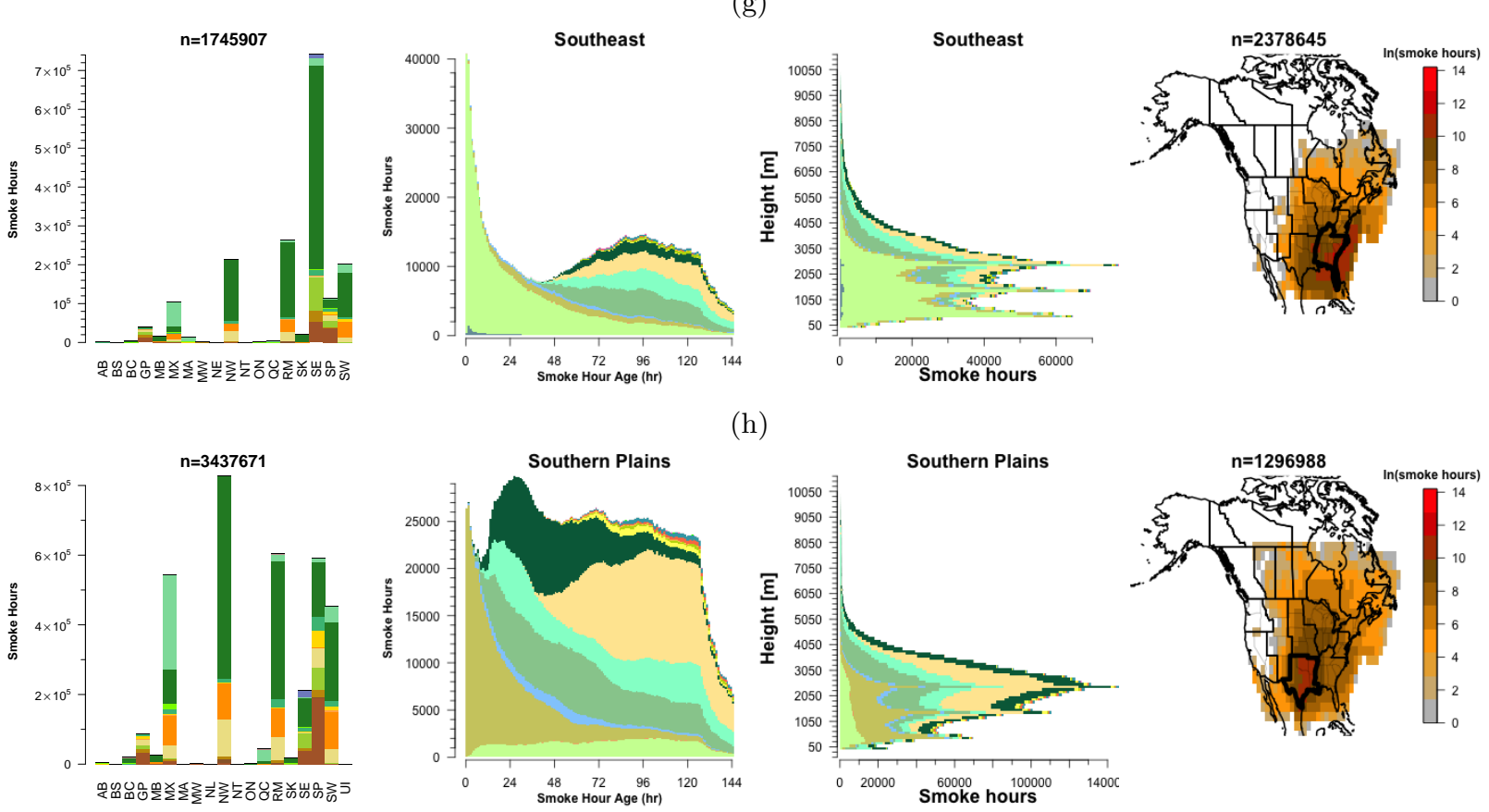

(h)
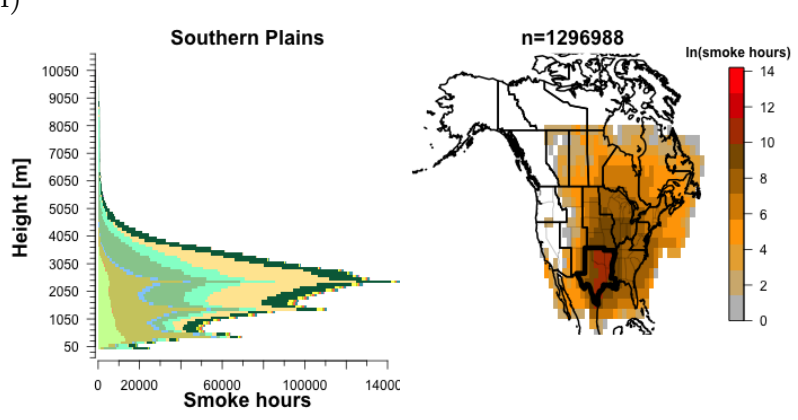

(i)

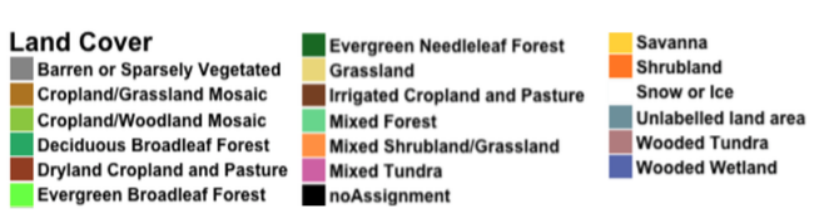

$\begin{array}{llllll}\text { Region } & \text { GP } \square \text { MX } \square \text { BC } \square \text { NU } \\ \square \text { NE } & \text { RM } \square \text { QC } \square \text { NB } \square \text { NT } \\ \square \text { MA } \square \text { SW } \square \text { NS } \square \text { PE } \square \text { CU } \\ \square \text { SE } \square \text { NW } \square \text { SK } \square \text { YT } \square \text { BS } \\ \square \text { MW } \square \text { AK } \square \text { AB } \square \text { MB } \\ \square \text { SP } \square \text { UI } \square \text { NL } \square \text { ON }\end{array}$



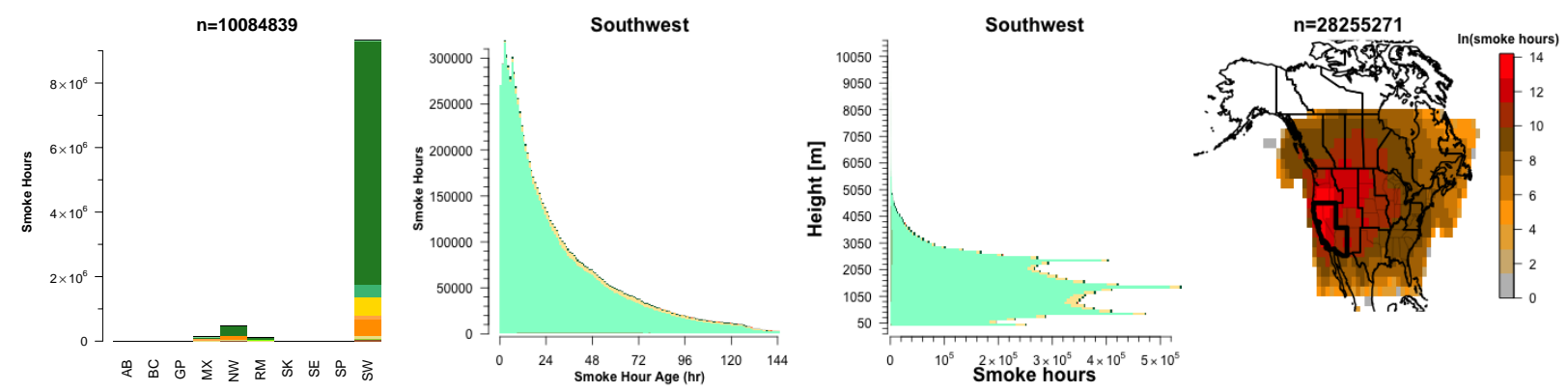

(j)

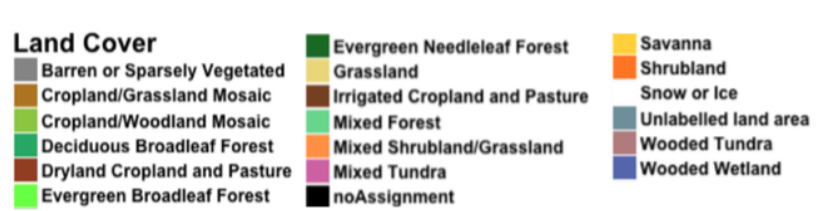

$\begin{array}{llllll}\text { Region } & \text { GP } \square \text { MX } \square \text { BC } \square \text { NU } \\ \square \text { NE } \square \text { RM } \square \text { QC } \square \text { NB } \square \text { NT } \\ \square \text { MA } \square \text { SW } \square \text { NS } \square \text { PE } \square \text { CU } \\ \square \text { SE } \square \text { NW } \square \text { SK } \square \text { YT } \square \text { BS } \\ \square \text { MW } \square \text { AK } \square \text { AB } \square \text { MB } \\ \square \text { SP } \square \text { UI } \square \text { NL } \square \text { ON }\end{array}$

Figure S6: June-September 2007-2014 regional smoke hour transport summaries. Column 1 shows the number of smoke hours in the region by source region and land cover classification. Only source regions with non-zero smoke hour contributions are shown. Column 2 shows the distribution of smoke age segregated by source region. Column 3 shows the distribution of smoke hour height segregated by source region. Column 4 shows the count of smoke hours produced by a region on a $2^{\circ} \times 2^{\circ}$ degree grid with consistent colorbar for all regions. The grid spans $18-180^{\circ} \mathrm{W}$ and $18-90^{\circ} \mathrm{N}$, a domain covering all five sectors where HMS analyzes smoke plumes (only a subset plotted). Shaded values are the natural log of the number of smoke hours in each grid cell. All figures generated using EDAS meteorology.

\section{S8 Winter heat maps for all regions:}

This section contains smoke hour heat maps for all regions with non-zero smoke hours produced in the months January through March years 2007 through 2014. The intention of these figures is to highlight possible smoke-hour false alarms, which are indicated by disconnected regions of smoke hours. 


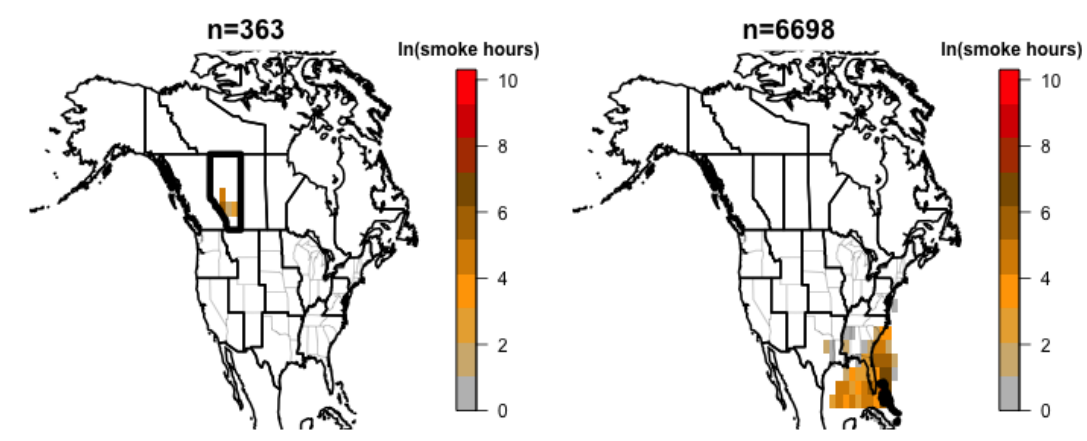

(a)

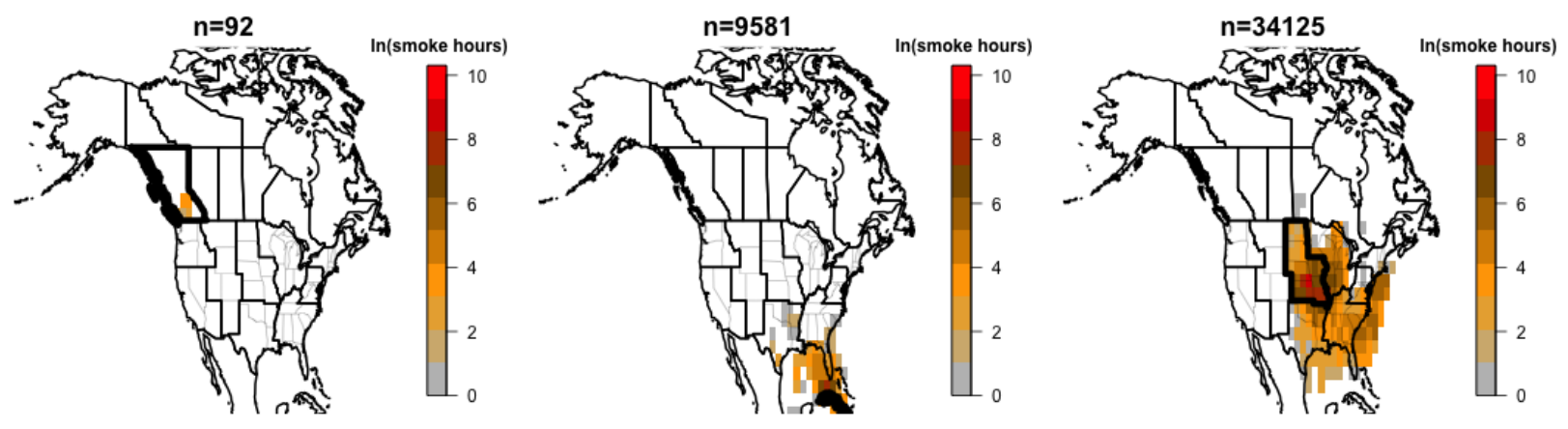

(b)

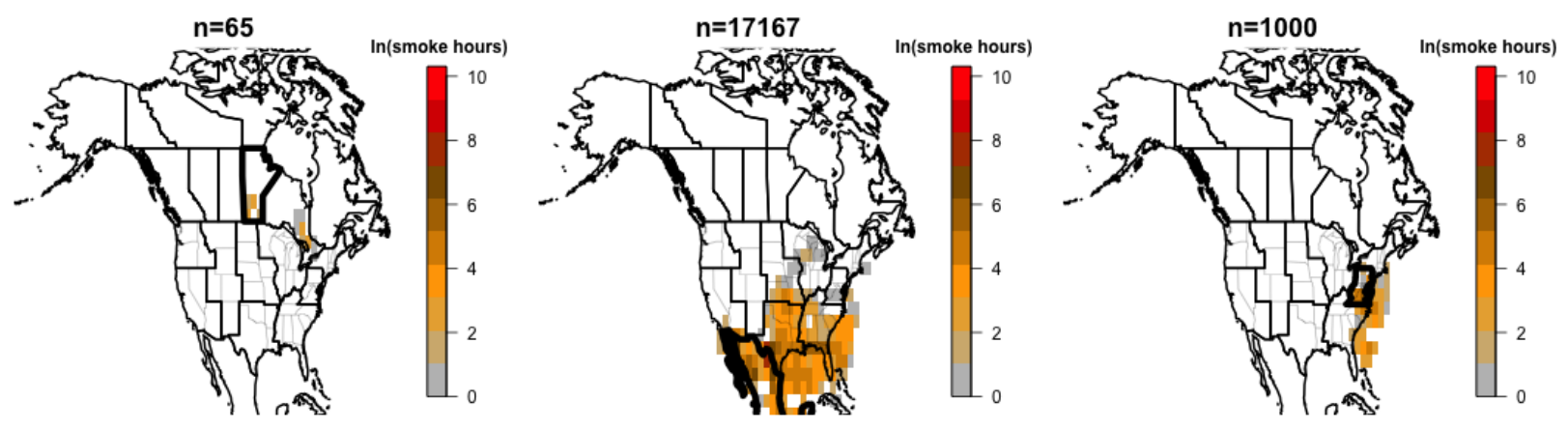

(c) 

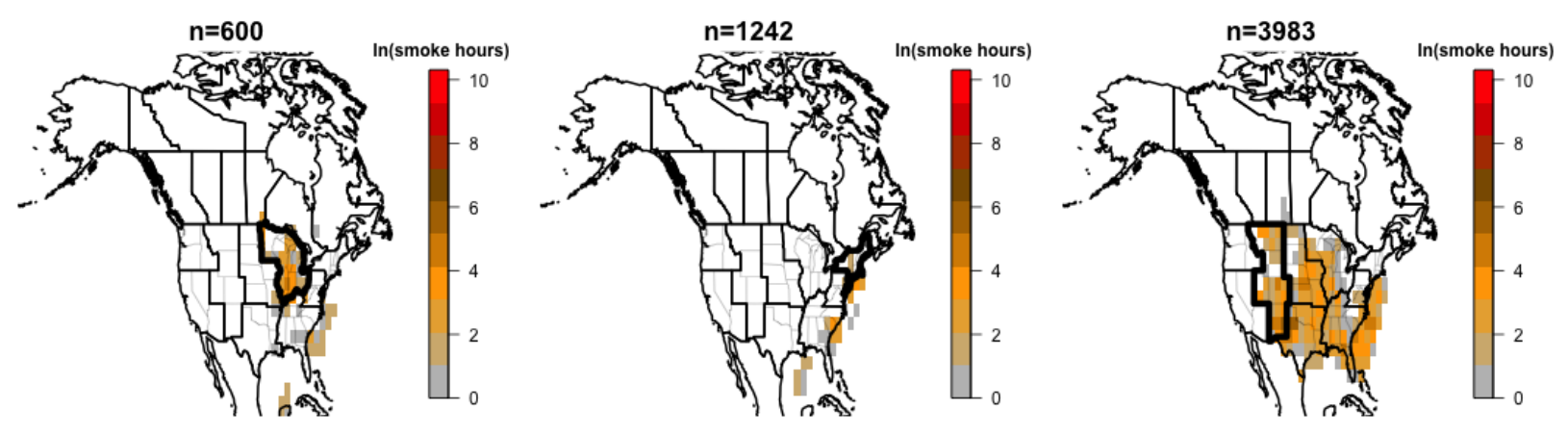

(d)
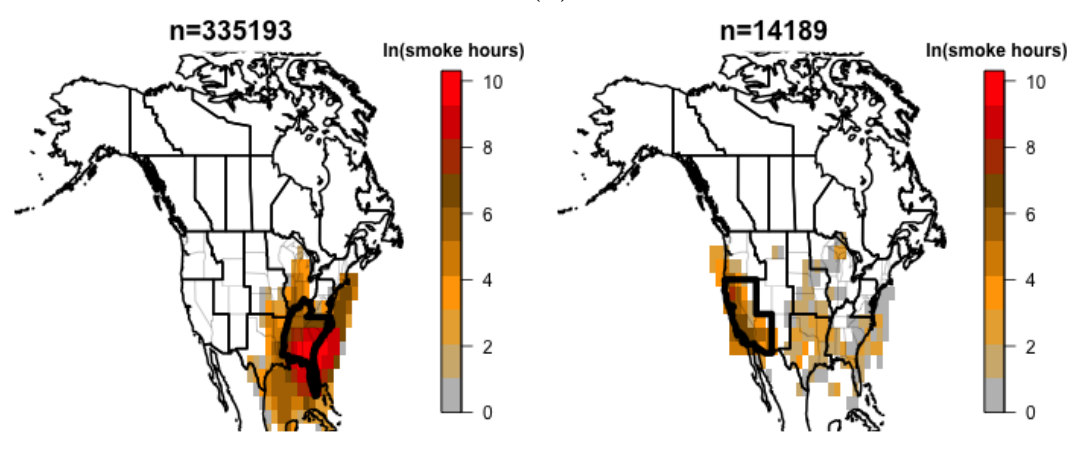

(e)
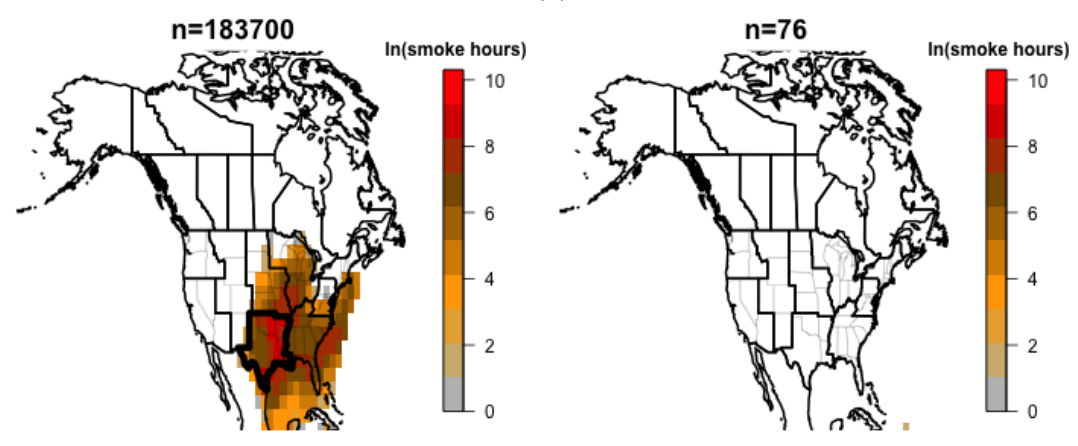

(f)

Figure S7: Total number of smoke hours produced by regions for months January-March between 2007 and 2014 using GDAS1 meteorology. Only regions with more than zero smoke hours produced are shown. Region labels are as follows; row A: (left to right) Alberta, Bahamas. Row B: British Columbia, Cuba, Great Plains. Row C: Manitoba, Mexico, Mid Atlantic. Row D: Midwest, Northeast, Rocky Mountains. Row E: Southeast, Southwest. Row F: Southern Plains, U.S. Islands. 


\section{S9 Description of observed weaknesses in land cover classification assignments:}

\section{S9.1 Comparison of 1990 AVHRR land cover data to 2010 MODIS/TERRA land cover data}

In this section we assign HYSPLIT points land cover using a dataset from the North American Land Cover Change Monitoring System. The specific dataset we choose to use within this system was the 2010 Land Cover of North America at 250 meters data published in 2013 by the Commission for Environmental Cooperation in Montral, Qubec, Canada (http://www.cec.org/tools-and-resources/map-files/land-cover-2010). These data are based on the Moderate Resolution Imaging Spectroradiometer (MODIS/TERRA) seven land spectral bands top of atmosphere reflectance. These data were created primarily to assess North America land cover changes between 2005 and 2010. Approximately 1\% of land area land cover classifications changed during this time period.

Overall we find that the differences between the two datasets are driven by an inconsistent list of land cover classifications between the 1992 and 2010 data. Comparing the two different land cover classifications is challenging and requires subjectivity due to the fact that the land cover classification categories are not the same between the 1992 and 2010 data. For example, when assessing whether the two datasets agree on land cover for a given location there needs to be a decision as to whether "Temperate or subpolar needleleaf forest" and "Evergreen Needleleaf Forest" count as a match. Instead of making this decision we show what land cover assignment would have been made for each HYSPLIT point had we used the 2010 data rather than the 1992 data using the same methods described in Sect 2.3 of the manuscript. The only difference is that we allow "Urban" land cover assignments to be made, as these updated data were created after many of the fires in our analysis occurred.

Figures S8 through S24 show what the 2010 land cover data would have assigned to HYSPLIT points for each type of 1992 land cover classification made. For example, Fig. S8 shows the location of HYSPLIT points where the 1992 data assigned the land cover type "cropland/grassland mosaic" and color codes them by the land cover that would have been assigned had we used the 2010 data. The bar graphs on the left shows the abundance of each 2010 data classification.

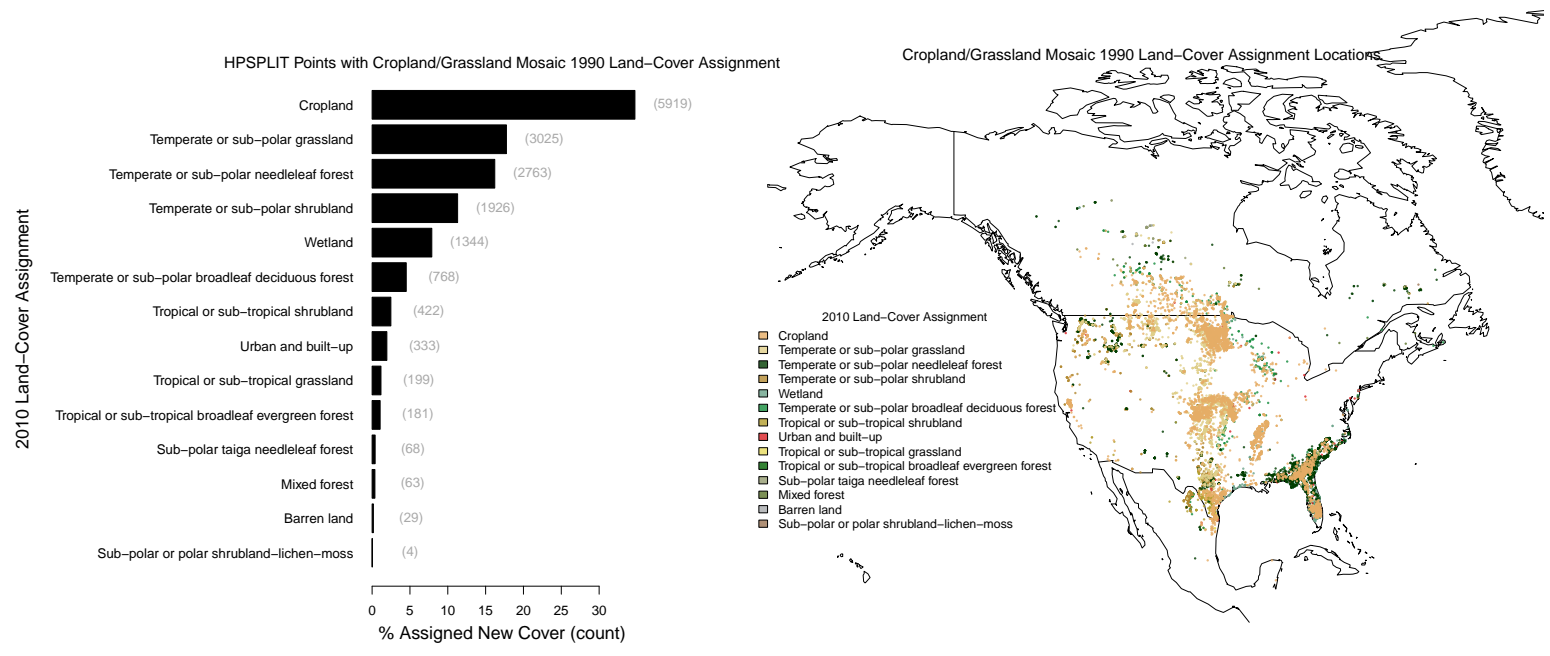

Figure S8 


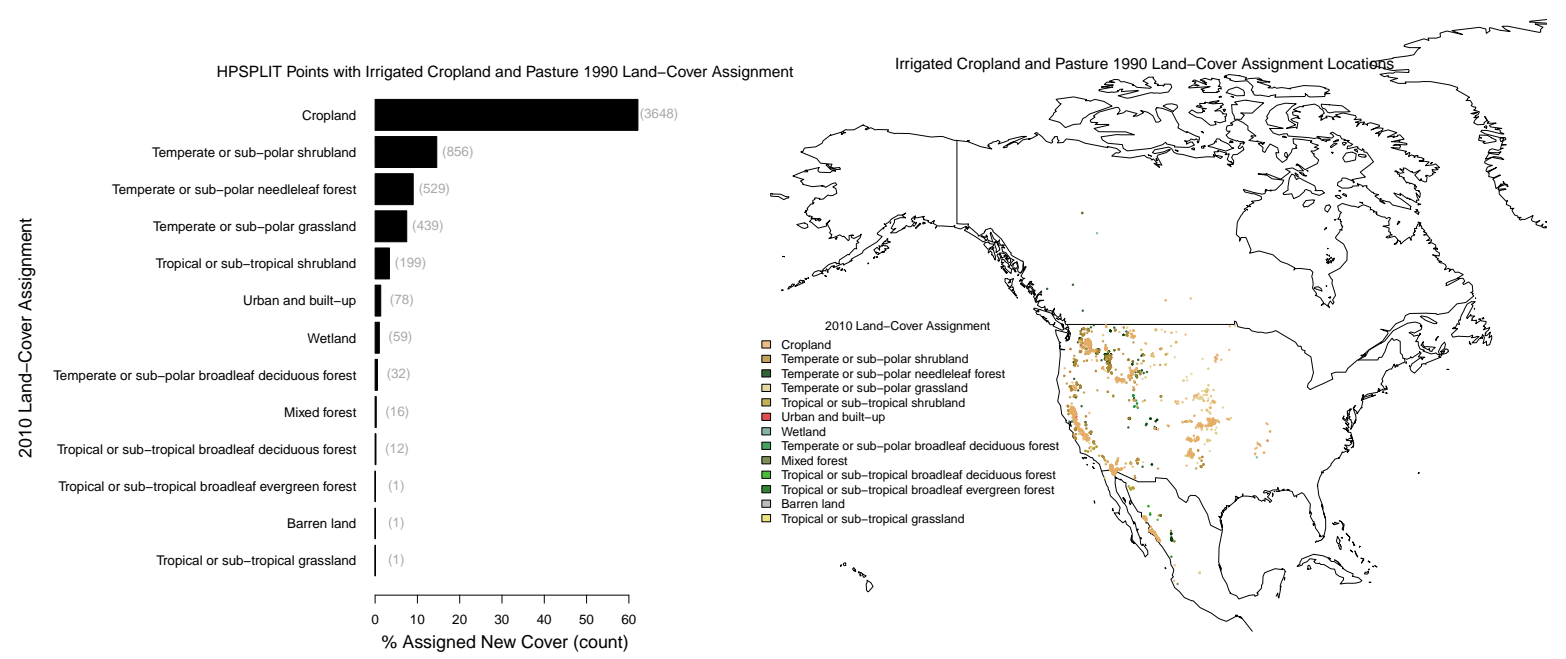

Figure S9

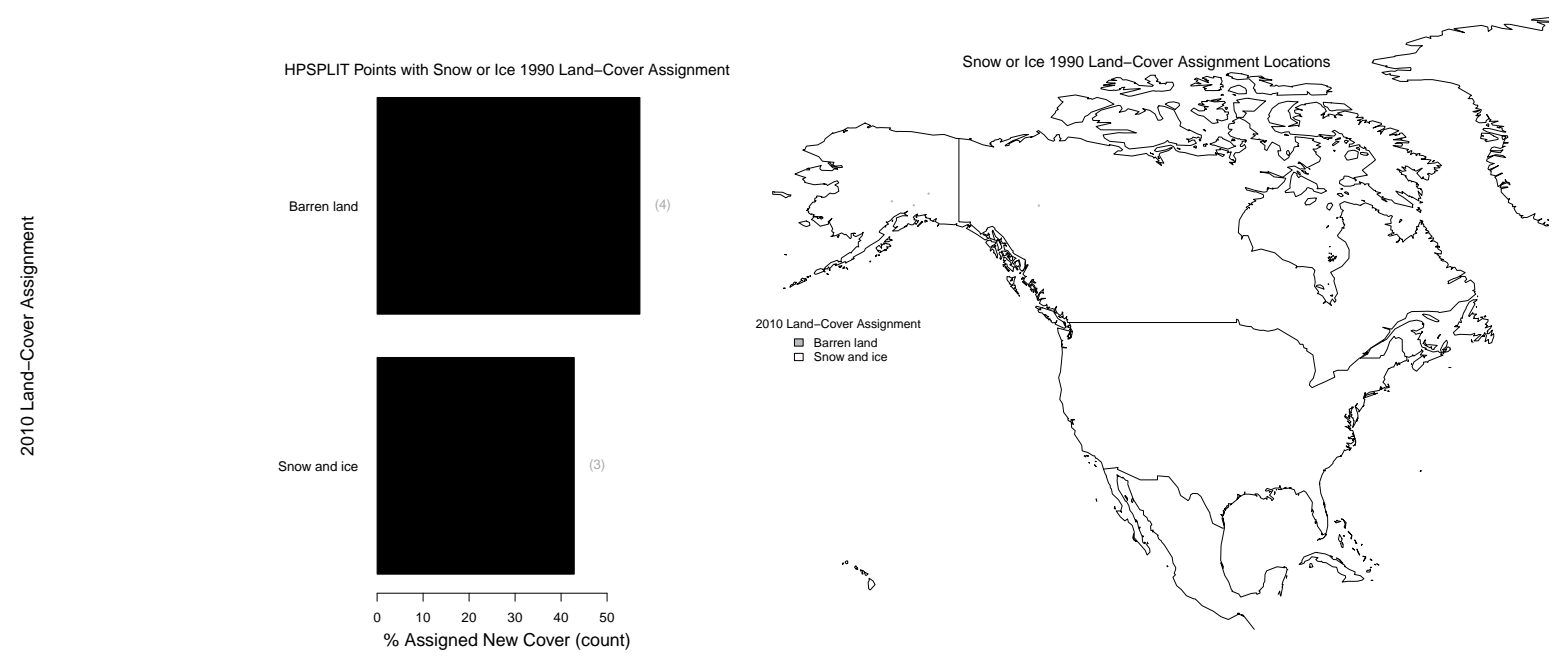

Figure S10 


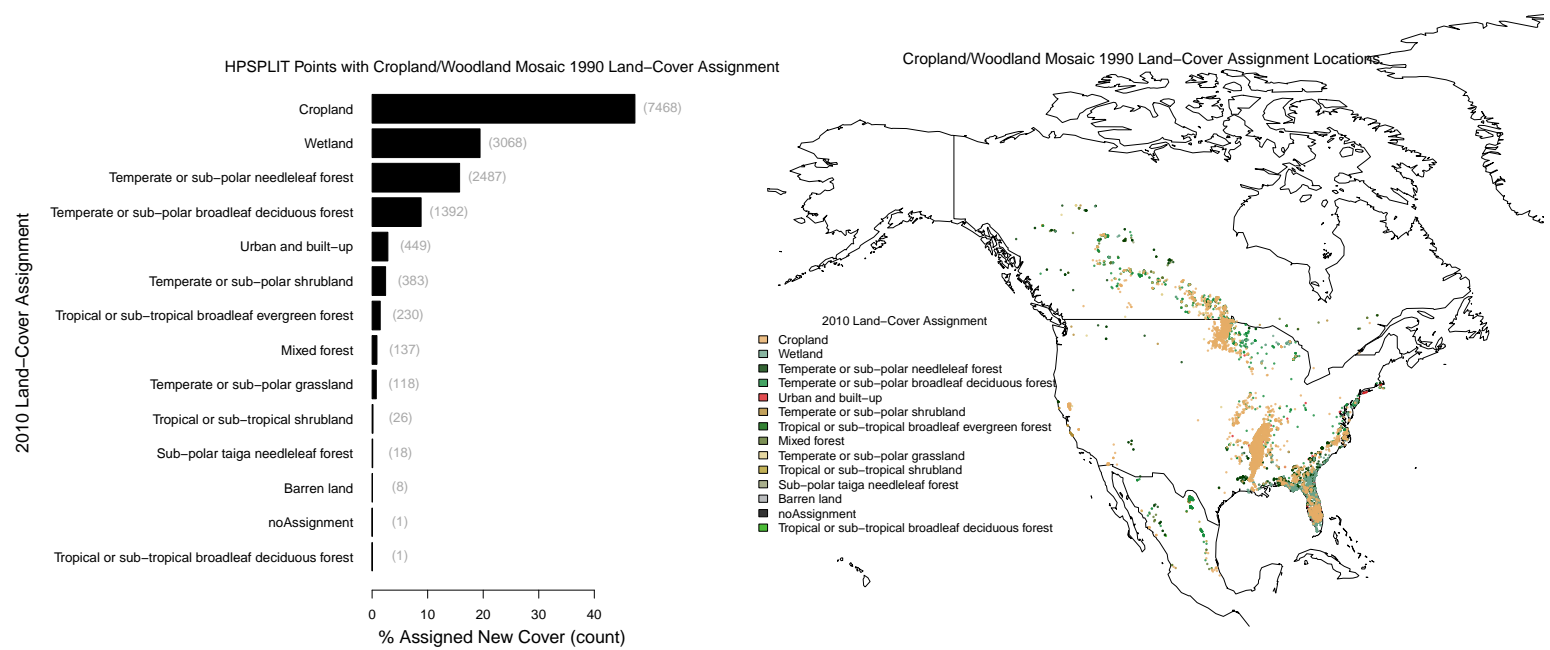

Figure S11
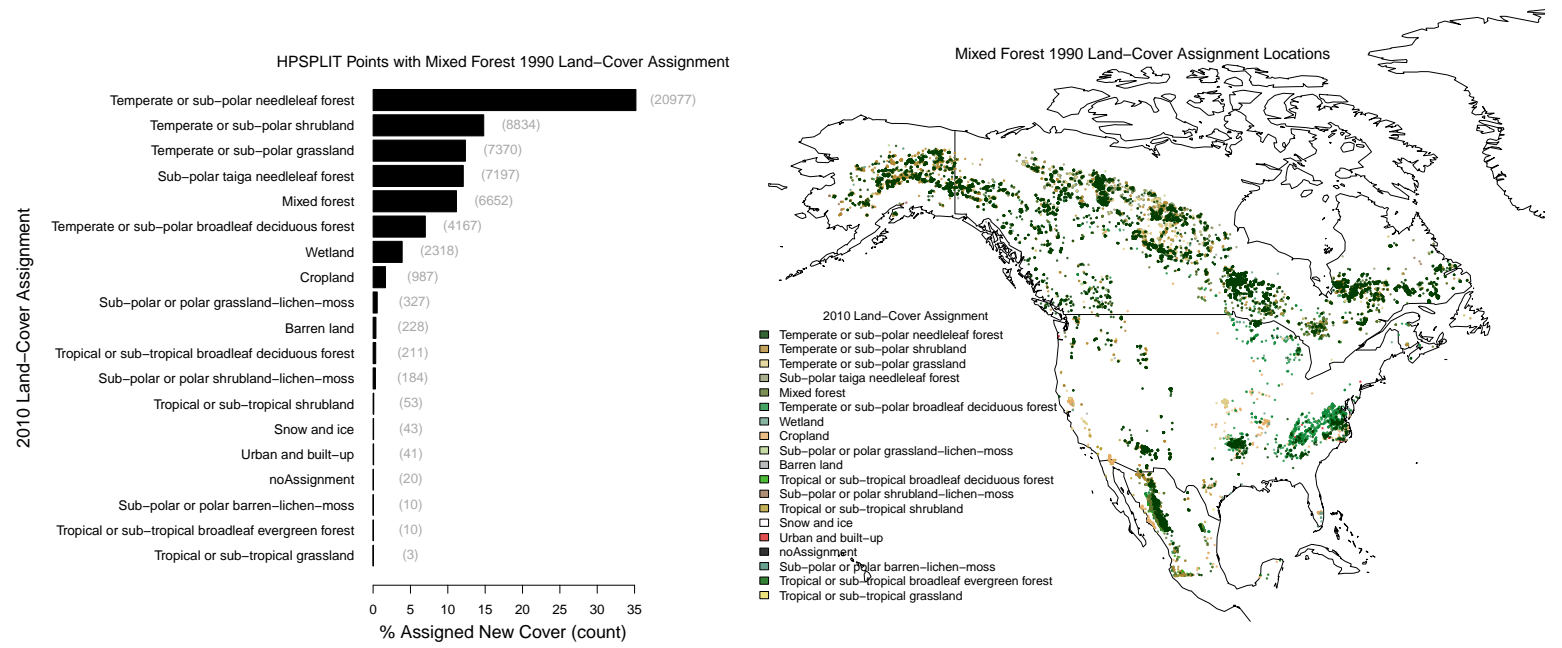

Figure S12 


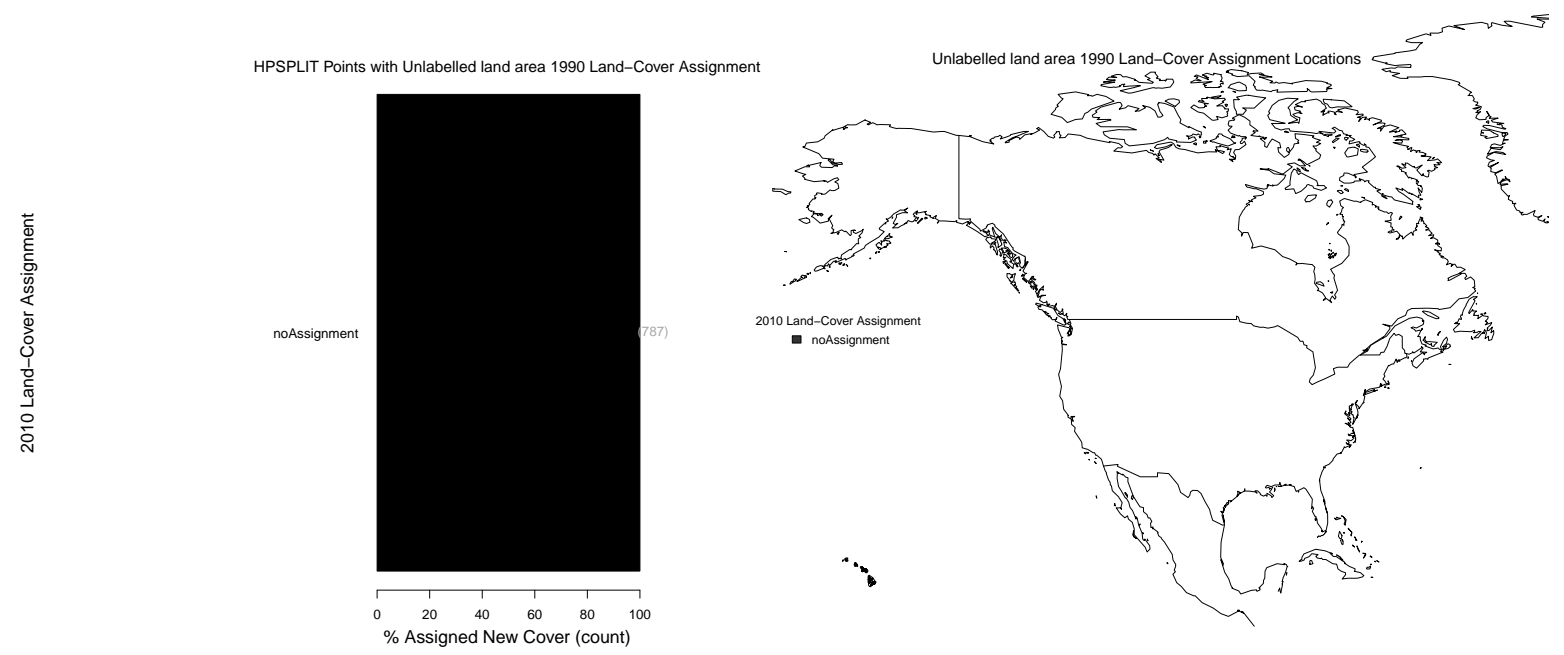

Figure S13

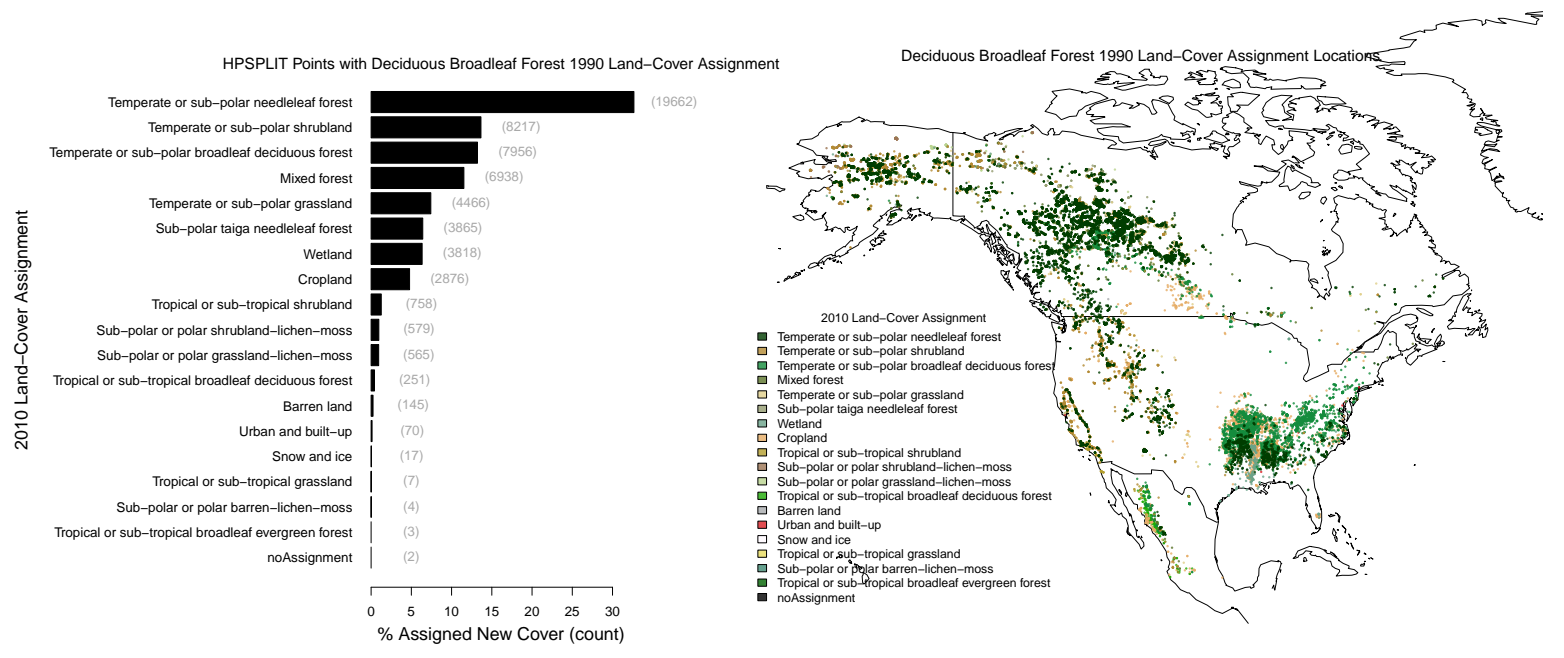

Figure S14 


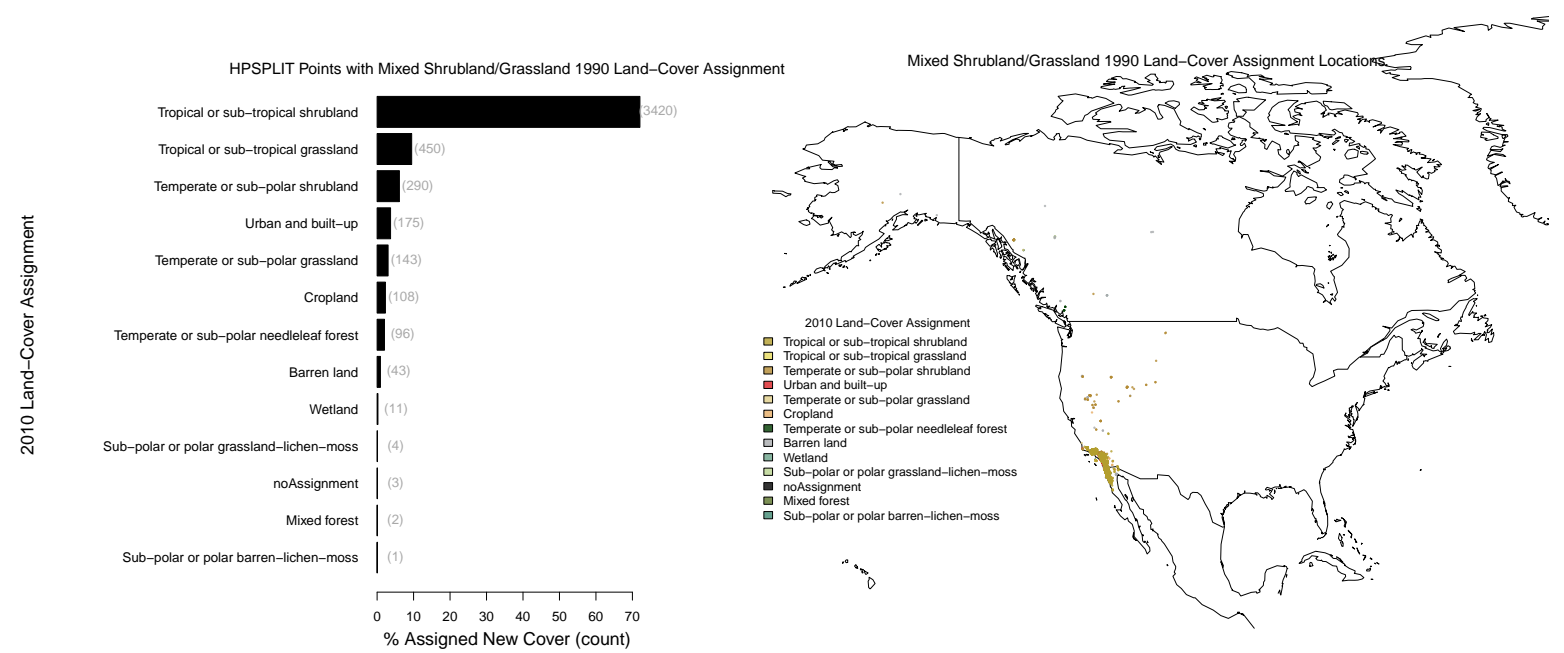

Figure S15

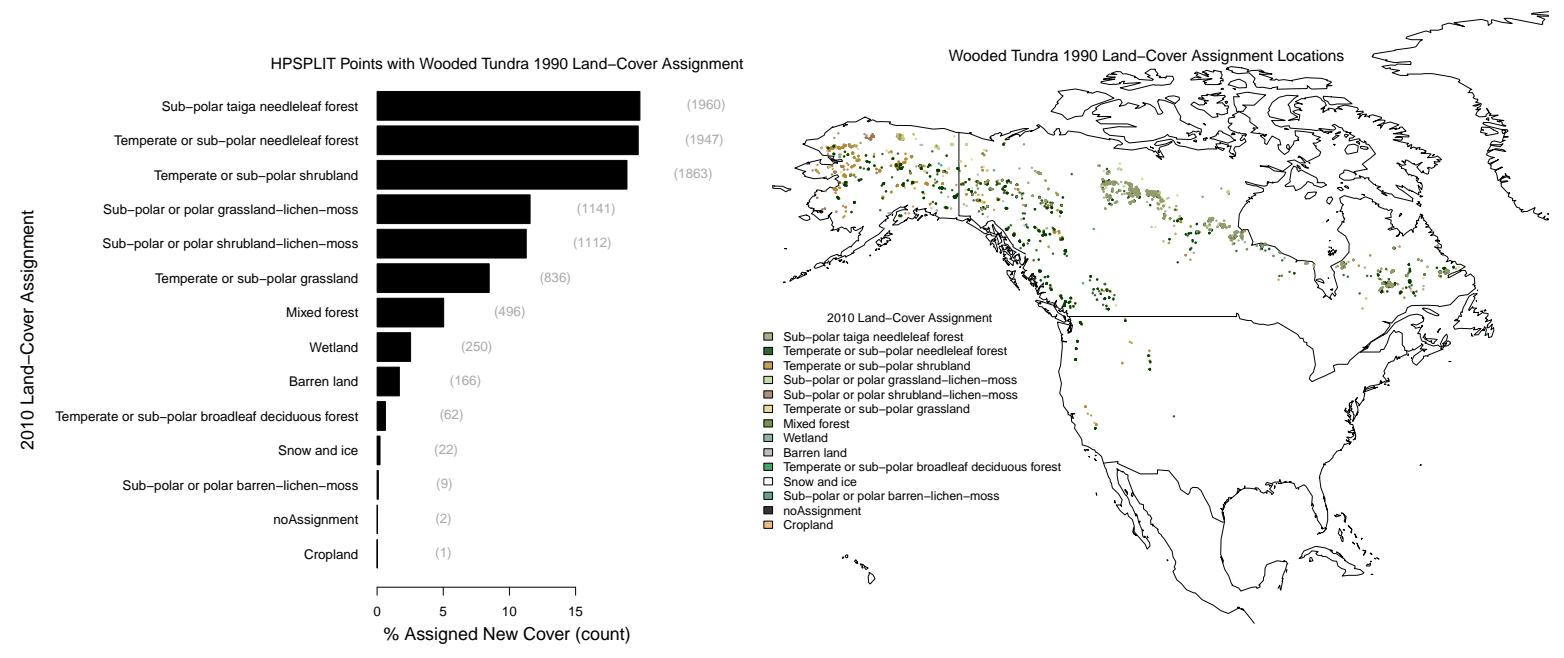

Figure S16 


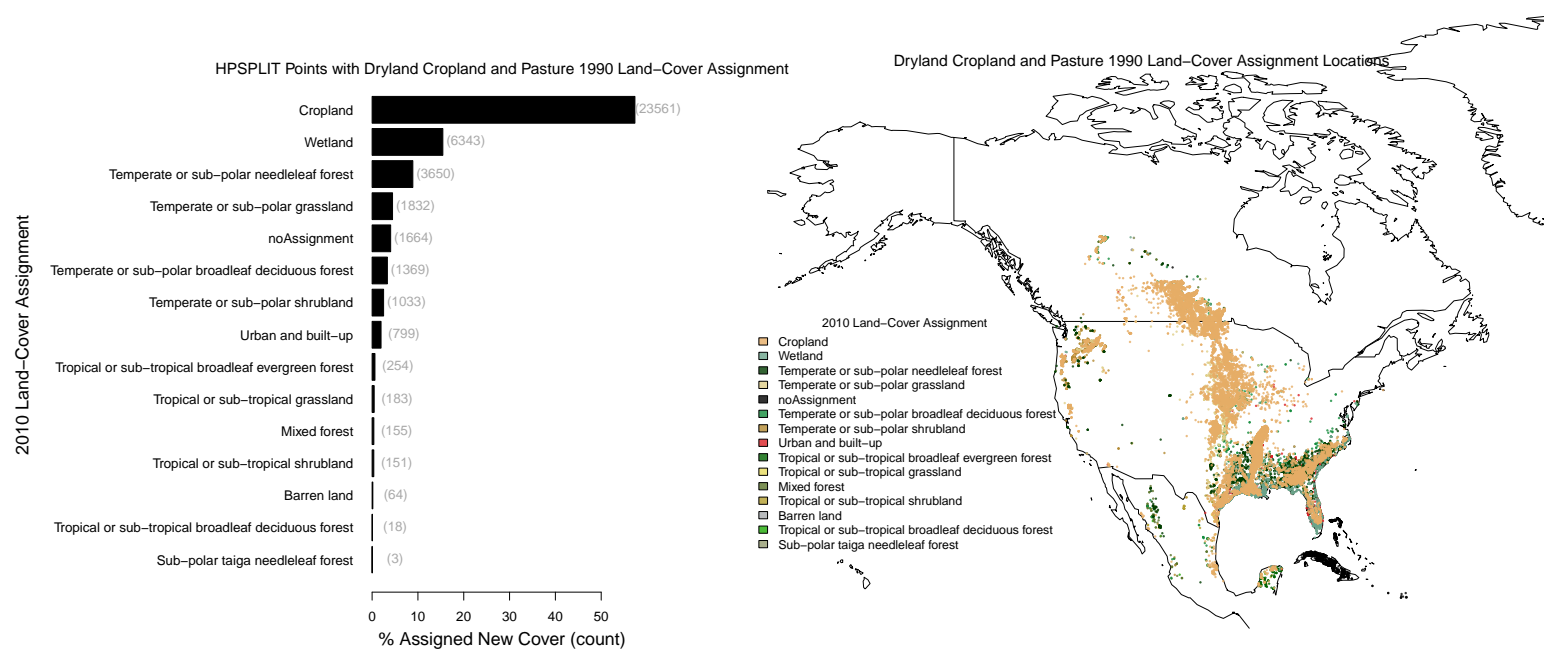

Figure S17

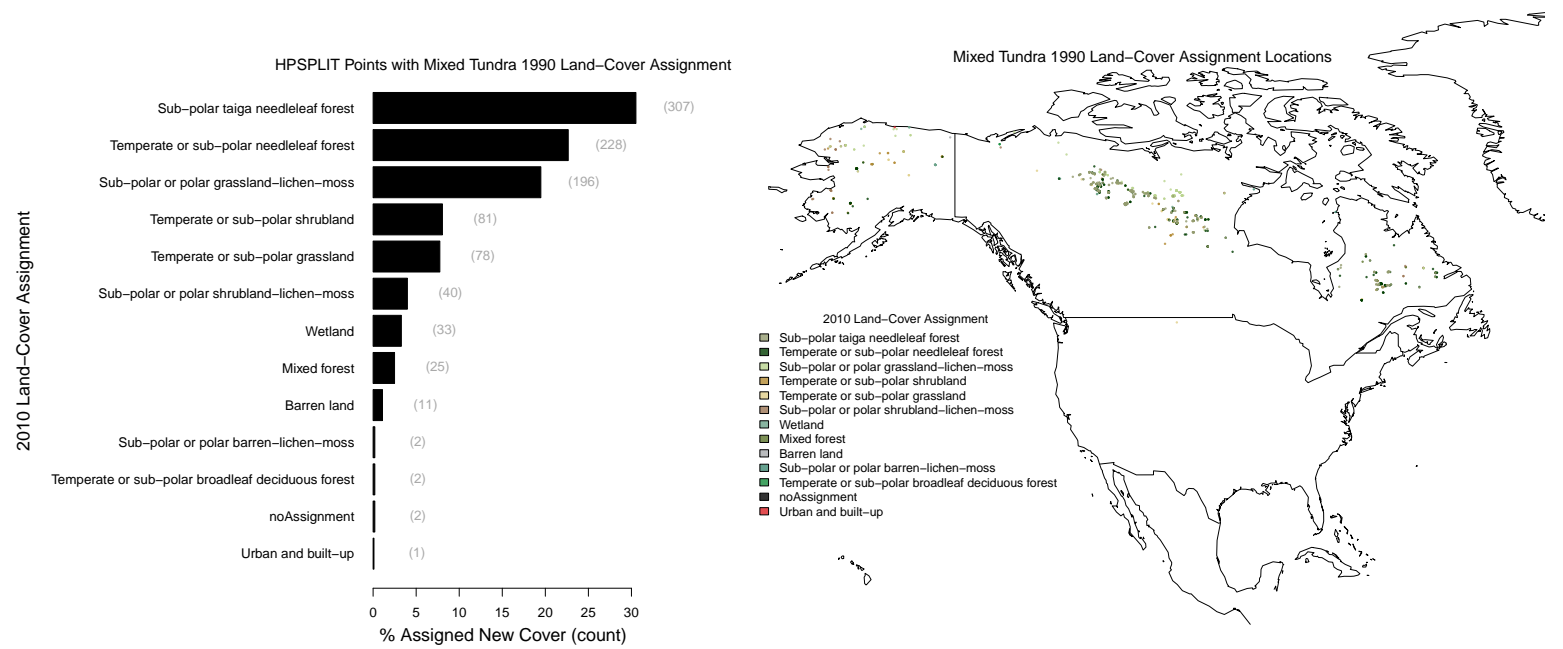

Figure S18 


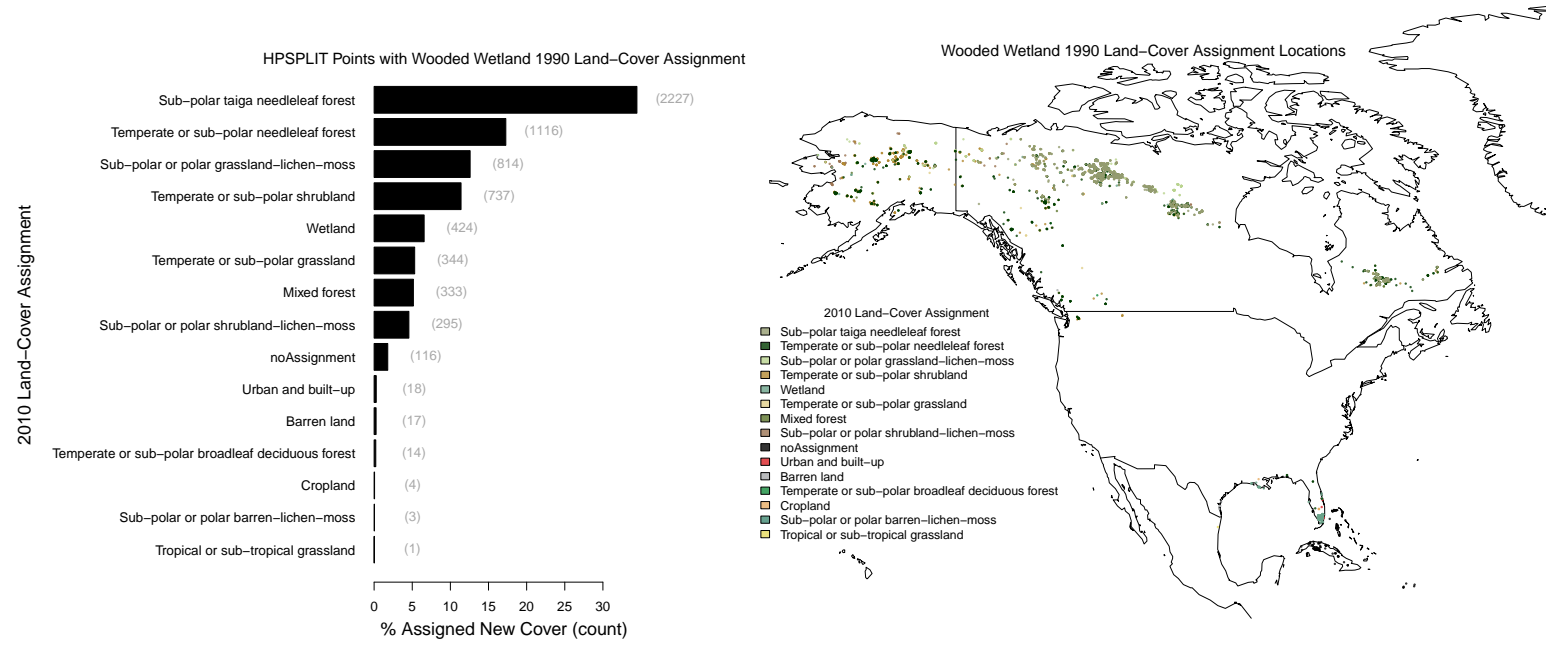

Figure S19

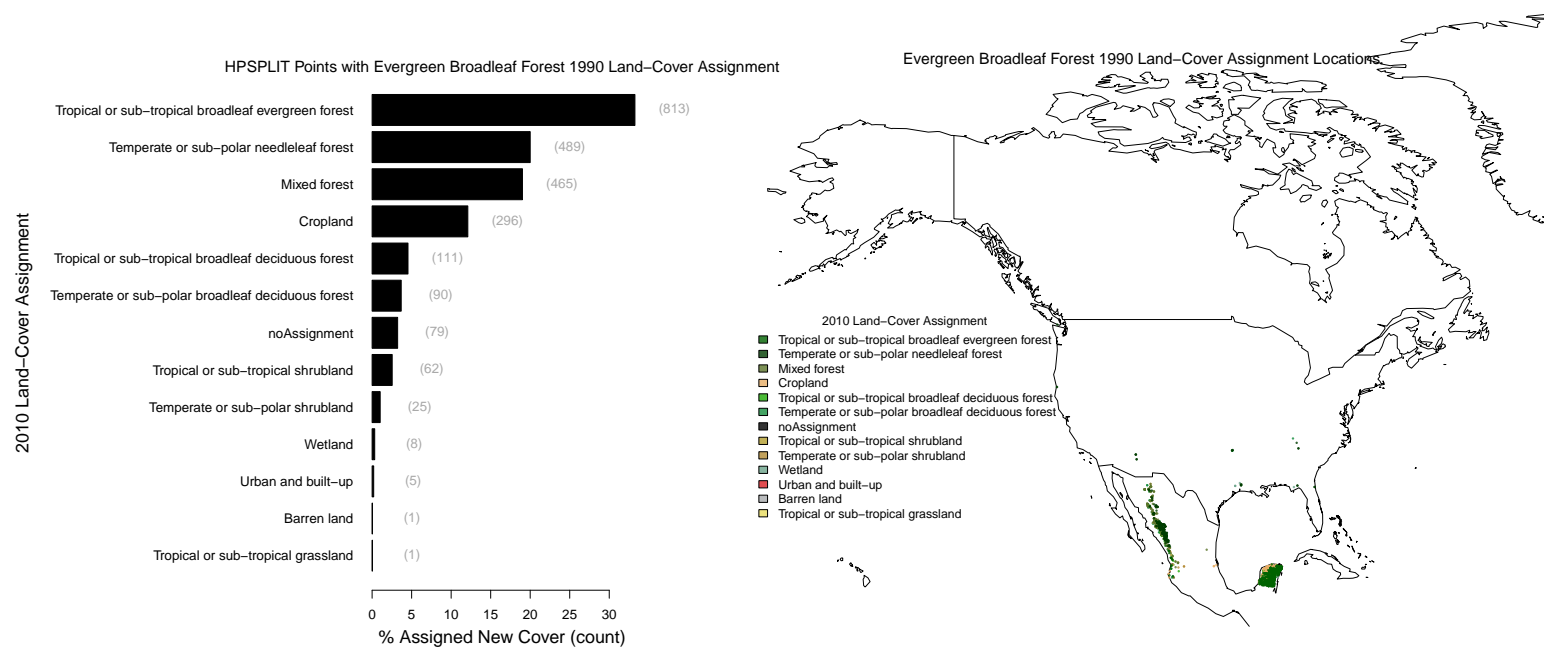

Figure S20 

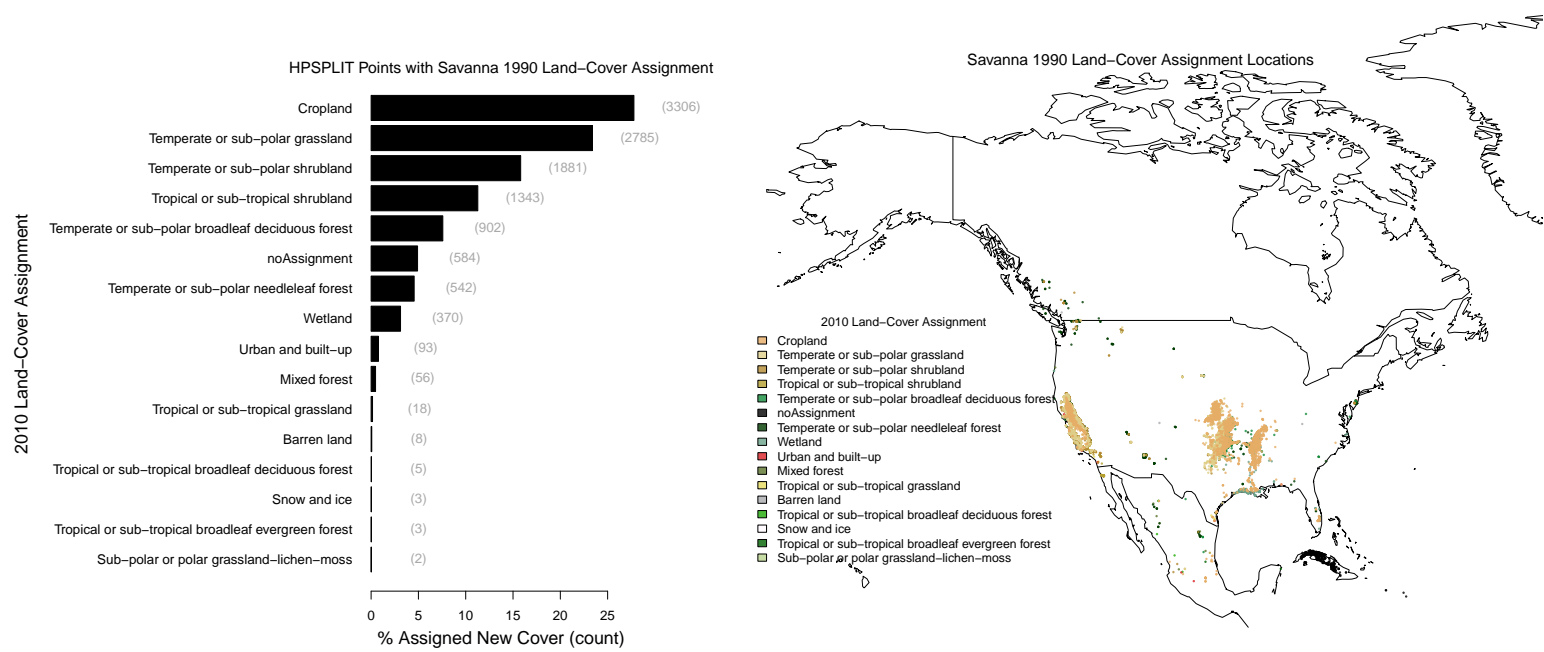

Figure S21

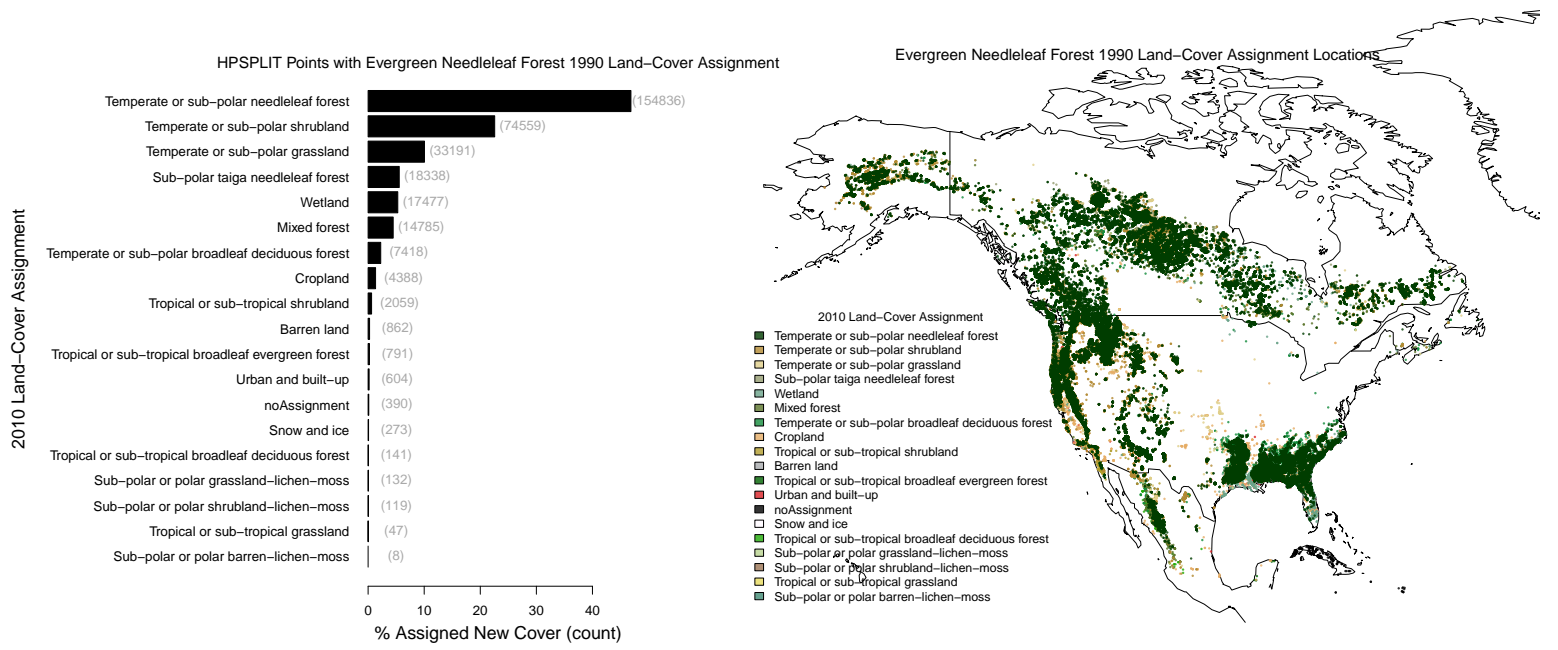

Figure S22 

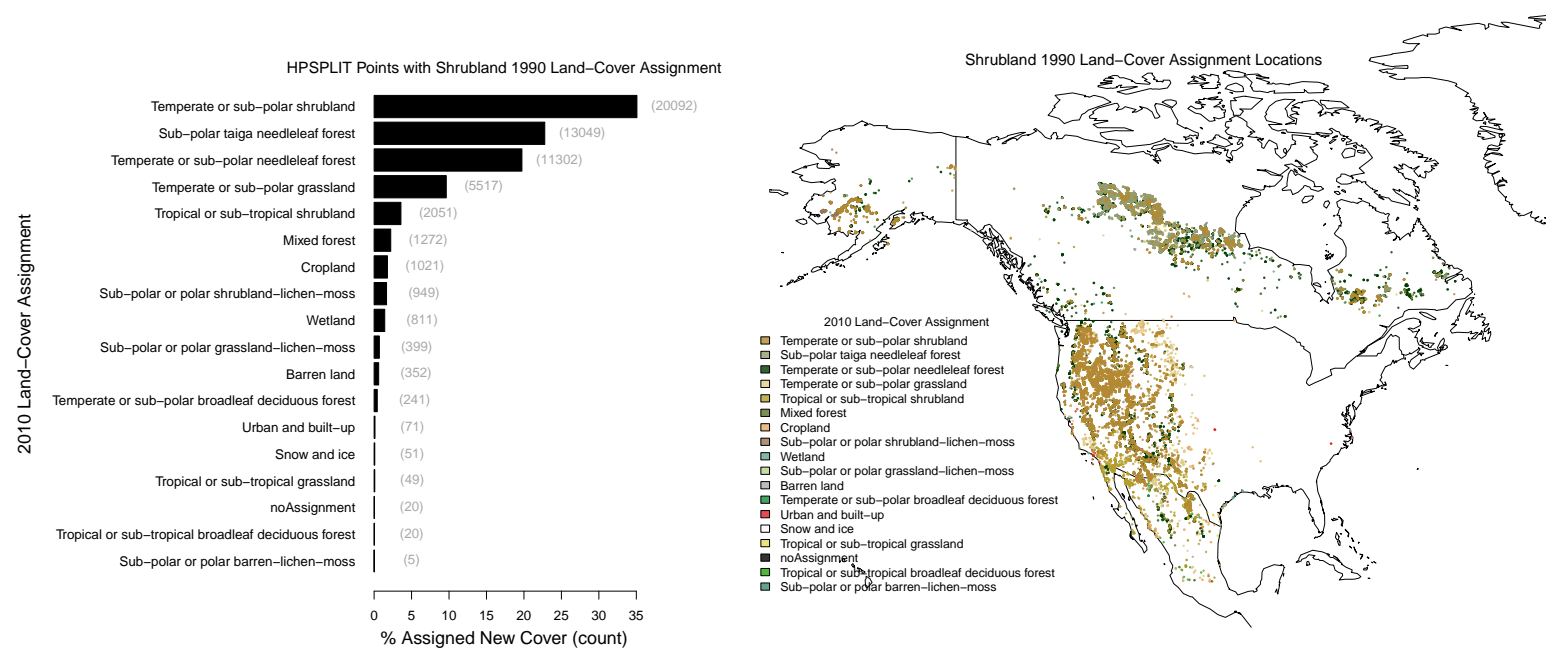

Figure S23
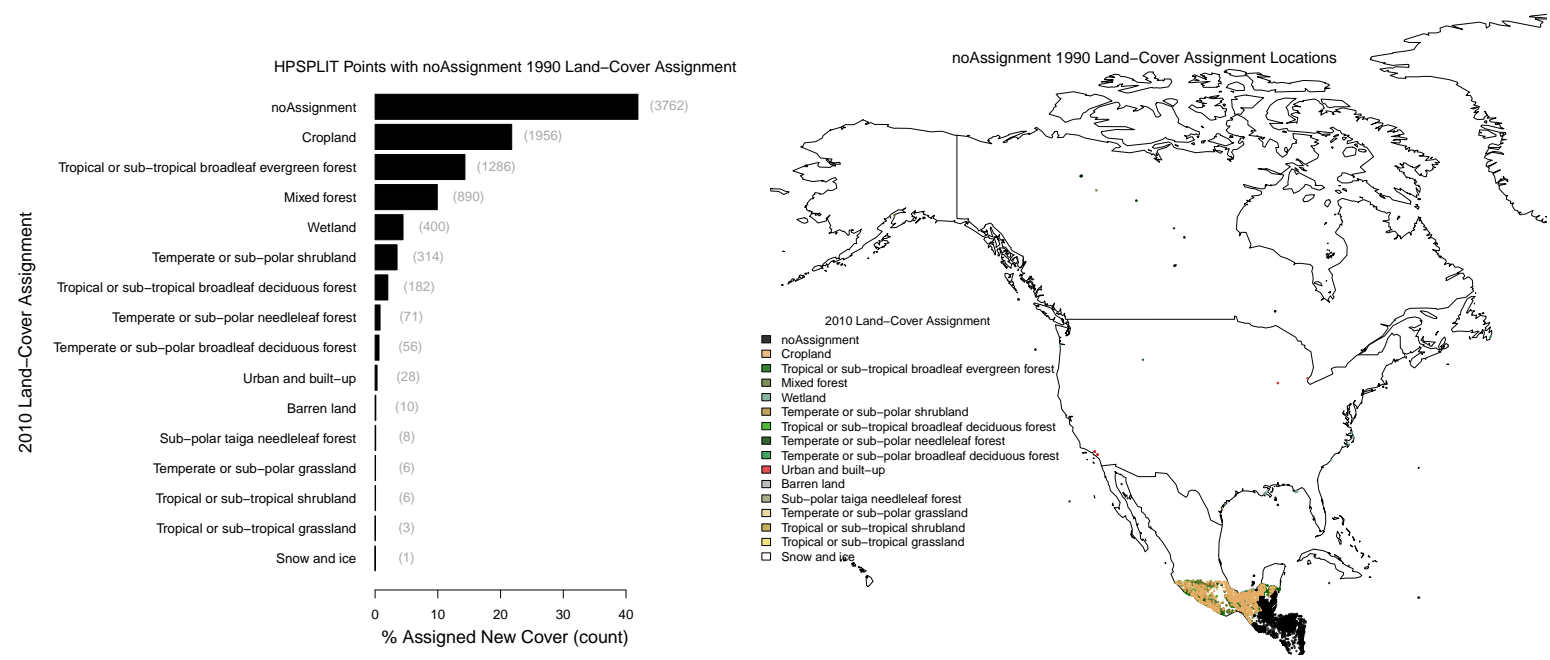

Figure S24

\section{S9.2 Comparison of 1990 AVHRR land-cover data to Google Earth visible im- agery}

The following weaknesses were observed when comparing the land cover assignment made using the methods described in Sect 2.3 of the manuscript to visible imagery provided by Google Earth. Steven Brey extensively audited the quality of the automated land cover assignments by plotting HYSPLIT point locations in Google Earth and using the visual imagery to make my own human assessment of the land cover. Determining plant species is not possible using this method, but it is possible to differentiate crops, grass, forest, water, and urban land cover types.

- Cropland and grassland seem to get mixed up in dry places. Heavily irrigated (green in visible Google Earth imagery) farmland appears to more regularly be classified as cropland. I observed that croplands in Eastern Colorado are often classified as grassland.

- The summit of Mount Rainier and Mount Baker are mixed forest. That is nonsense as these are heavily glaciated peaks and this dataset does have glaciers and snow cover. It correctly assigned snow and ice to the summit of a mountain in the Alaskan Range. 
- There is also a consistent issue with assigning forest land cover classifications to agriculture in Western Washington. Because of the age of this dataset it is possible that this was indeed forest in the early 90 s and has since been converted to cropland.

- At the interface between grass, shrubs and forests it takes a considerable distance to transition assignments to forest. For example, the data assign Arthurs Rock in Lory State Park Colorado, a forested area, as grassland.

- There are around $\sim 10,000$ HYSPLIT points $(\sim 1.3 \%)$ that are not given a land type assignment because the land cover data is convinced they are in urban areas or water, which my current methods do not allow. One example of when my methods fail is the HYSPLIT point that occurred on 2005-0929 at $(34.195,-118.259)$, near the middle of the Verdugo Mountains in Southern California. These mountains are less then $5 \mathrm{~km}$ across and are surrounded by expansive heavily developed cities that include Pasadena, Glendale, and Burbank California.

Overall the land cover assignments seem to make sensible assignments. For the purpose of distinguishing crops from forest from shrubs this dataset and methods described in Sect 2.3 of the manuscript appear affective.

\section{S10 Additional HMS smoke plume operational analysis details}

Presently, there is no comprehensive validation of HMS smoke plume analysis. One of the reasons in that there is no spatially and temporally comprehensive ground truth to compare to. Other satellite data would need to be used and these would have their own uncertainties. In the manuscript we state that the largest uncertainty for the smoke plume analysis is likely to be the edges of the smoke plume. In aggregate this is true, but may not be the largest uncertainty for every individual smoke plume. Below is an example of how the edge of a smoke plume can be uncertain, as described by an HMS analyst.

Description of smoke plume analysis on 9/23/2017: We [HMS analyst] observed agricultural burning in the mid/lower Mississippi Valley the day before (Fri 9/22/2017). When I was drawing my smoke on the morning of the 23rd I could see a remnant plume from the previous evening that was clearly associated with one of the larger fires and it was somewhere over southwest MO and vicinity. This plume was attached to a larger area of lighter density smoke that extended to the east into the Ohio Valley. As is typical in the eastern half of the US in the summer there was also sulfate haze. Since there was no hard edge on the eastern extent of the smoke I had to make a best guess as to how far the smoke extended. The problem is most pronounced with larger smoke plumes as they become more detached from the source fire since they gradually disperse and lose their sharp edge.

Many of the archived smoke polygons have straight-line edges particularly during the summer and over the ocean. The straight edges signify a boundary in which smoke-plume-detection analysis is performed. The smoke-plume-detection analysis is performed in five sectors. Each sector displays satellite imagery in a Lambert conic conformal projection. After analysis in all five regions has been performed, they are pieced together to form a single analysis. Strait edges of individual smoke GIS polygons occur when smoke plumes from different regions are pieced together. Not all sectors are analyzed year round. There is no analysis for Alaska or Northern Canada between November 1st and May 1st.

There is not always a HYSPLIT point associated with every smoke plume and vice versa. Often (especially during the summer when there are many wildfires producing a large amount of smoke) analysts observe smoke that has drifted a long way and become detached from the fire that produced it. In this case the smoke plume is not associated with any HYSPLIT points on that day. For example, the wildfires in Alaska and Northern Canada in 2015 produced smoke that drifted southeast into the Great Lakes and Mid Atlantic region and eventually reached Europe. This transport occurred over several weeks. When HMS analysts drew the smoke plumes as they traveled over the eastern part of the U.S., they did not associate the smoke with HYSPLIT points from the current day. There are also instances of HYSPLIT points when no smoke plumes are analyzed. For example, this can occur when HYSPLIT points are analyzed where there are many small fires, but no smoke plume analysis is done due to cloud cover. 


\section{S11 Code repository:}

In an effort to be as open, transparent, and reproducible as possible, all work associated with this project is stored in the following subversion repository: http://salix.atmos.colostate.edu/svn/smokeSource/. This repository includes every version of all code, figures, and writing associated with this project. Please direct questions about this repository to sjbrey@rams.colostate.edu.

\section{S12 Interactive Version of Figure 13:}

A R Shiny application allows for interactive exploration of manuscript Fig. 13, including the ability to add or remove regions, as well as change between EDAS and GDAS meteorology. https://stevenjoelbrey. shinyapps.io/smokeWheel/

The Code for the app is located here: https://github.com/stevenjoelbrey/smokeWheel

\section{References}

Draxler, Roland R., and G. D. Hess. An Overview of the HYSPLIT_4 Modeling System of Trajectories, Dispersion, and Deposition. Australian Meteorological Magazine 47, no. 4 (December 1, 1998): 295308.

Stein, A. F., R. R. Draxler, G. D. Rolph, B. J. B. Stunder, M. D. Cohen, and F. Ngan. NOAAs HYSPLIT Atmospheric Transport and Dispersion Modeling System. Bulletin of the American Meteorological Society 96, no. 12 (May 4, 2015): 205977. doi:10.1175/BAMS-D-14-00110.1.

Draxler, Roland. NOAA - Air Resources Laboratory - FAQ - How Do I Estimate the Absolute (in Km) and Relative (\%) Errors When Using the HYSPLIT Trajectory Model?, September 23, 2008. http://www.arl.noaa.gov/faq_hg11.php.

Kanamitsu, Masao. Description of the NMC Global Data Assimilation and Forecast System. Weather and Forecasting 4, no. 3 (September 1, 1989): 33542. doi:10.1175/15200434(1989)004¡0335:DOTNGD ¿2.0.CO;2.

Val Martin, M., J. A. Logan, R. A. Kahn, F.-Y. Leung, D. L. Nelson, and D. J. Diner. Smoke Injection Heights from Fires in North America: Analysis of 5 Years of Satellite Observations. Atmos. Chem. Phys. 10, no. 4 (February 15, 2010): 14911510. doi:10.5194/acp-10-1491-2010.

Paugam, R., M. Wooster, S. Freitas, and M. ValMartin. A Review of Approaches to Estimate Wildfire Plume Injection Height within Large-Scale Atmospheric Chemical Transport Models. Atmos. Chem. Phys. 16, no. 2 (January 26, 2016): 90725. doi:10.5194/acp-16-907-2016. 